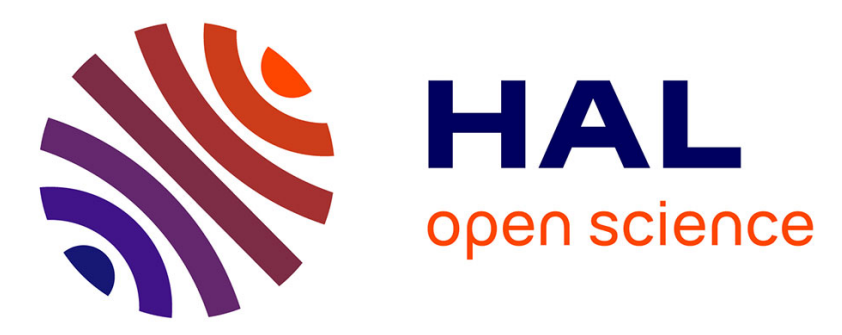

\title{
Conceptual model of fracture-limited sea cliff erosion: erosion of the seaward tilted flyschs of Socoa, Basque Country, France
}

Mélody Prémaillon, Thomas Dewez, Vincent Regard, Nick J Rosser, Sébastien Carretier, Lucie Guillen

\section{To cite this version:}

Mélody Prémaillon, Thomas Dewez, Vincent Regard, Nick J Rosser, Sébastien Carretier, et al.. Conceptual model of fracture-limited sea cliff erosion: erosion of the seaward tilted flyschs of Socoa, Basque Country, France. Earth Surface Processes and Landforms, 2021, 46 (13), pp.2690-2709. 10.1002/esp.5201 . hal-03272984v2

\section{HAL Id: hal-03272984 \\ https://hal.science/hal-03272984v2}

Submitted on 7 Jul 2021

HAL is a multi-disciplinary open access archive for the deposit and dissemination of scientific research documents, whether they are published or not. The documents may come from teaching and research institutions in France or abroad, or from public or private research centers.
L'archive ouverte pluridisciplinaire HAL, est destinée au dépôt et à la diffusion de documents scientifiques de niveau recherche, publiés ou non, émanant des établissements d'enseignement et de recherche français ou étrangers, des laboratoires publics ou privés. 


\title{
Conceptual model of fracture-limited sea cliff erosion: erosion of the seaward tilted flyschs of Socoa, Basque Country, France
}

\author{
Prémaillon Mélody ${ }^{1}$, Dewez Thomas J.B. ${ }^{2}$, Regard Vincent ${ }^{1,{ }^{*}}$, Rosser Nick J. ${ }^{3}$,
} Carretier Sébastien ${ }^{1}$, Lucie Guillen²

1: GET, Université de Toulouse, UPS (OMP), CNRS, IRD, 14 avenue Edouard Belin, 31400 Toulouse, France 2: BRGM (Bureau de Recherches Géologiques et Minières), 45060 Orléans, France

3: Department of Geography, Durham University, Lower Mountjoy, South Road, Durham DH1 3LE, UK *: corresponding author Vincent.regard@get.omp.eu / +33 561332645

\section{Abstract}

Sea cliff morphology and erosion rates are modulated by several factors, including rock control that reflects both lithology and rock structure. Erosion is anticipated to preferentially exploit "fractures", broadly meant as any discontinuity in an otherwise continuous medium, where the rock mass is weakest. Unpicking the direct control of such fractures on the spatial and temporal pattern of erosion remains, however, challenging. To analyze how such fractures control erosion, we monitored the evolution of a $400 \mathrm{~m}$ long stretch of highly-structured sedimentary cliffs in Socoa, Basque Country, France. The rock is known as the Socoa Flysch Formation. This formation combines decimeter-thick turbidites composed of repeat triplets of medium to strong calcareous sandstone, laminated siltstones and argillaceous marls. The sequence plunges at $45^{\circ}$ into the sea with a shore-parallel strike. The cliffs are cross-cut by two normal and reverse fault families, with $10-100 \mathrm{~m}$ alongshore spacing, with primary and secondary strata bound fractures perpendicular to the bedding, which combined delimit the cliff rock mass into discrete blocks that are exploited by erosion process. 
Erosion, and sometimes plucking, of such beds and blocks on the cliff face was monitored using ground-based Structure-from-Motion (SfM) photogrammetry, over the course of 5.7 years between 2011 and 2017. To compare with longer time change, cliff-top retreat rate was assessed using SfM-orthorectified archive aerial photographs spanning 1954 - 2008. We show that the $13,250 \mathrm{~m}^{2}$ cliff face released 4500 blocks exceeding $1.45 \times 10^{-3} \mathrm{~m}^{3}$, removing a total volume of $170 \mathrm{~m}^{3}$. This equates to an average cliff erosion rate of $3.4 \mathrm{~mm} / \mathrm{yr}$, which is slightly slower than the 54-year-long local cliff top retreat $(10.8 \pm 1.8 \mathrm{~mm} / \mathrm{yr})$.

The vertical distribution of erosion reflects the height of sea water inundation, where the maximum erosion intensity occurs ca. $2 \mathrm{~m}$ above high spring-tide water level. Alongshore, the distribution of rockfall scars is concentrated along bed edges bounding cross-cutting faults; the extent of block detachment is controlled by secondary tectonic joints, which may extend through several beds locally sharing similar mechanical strength; and, rockfall depth is always a multiple of bed thickness.

Over the longer-term, we explain block detachment and resultant cliff collapse as a cycle. Erosion nucleates on readily exploitable fractures but elsewhere, the sea only meets defect free medium-strong to strong rock slabs offering few morphological features for exploitation. Structurally delimited blocks are quarried, and with sufficient time, carves semi-elliptic scars reaching progressively deeper strata to be eroded. Lateral propagation of erosion is directed along mechanical weaknesses in the bedding, and large episodic collapses affect the overhanging slabs via sliding on the weak marl beds. Collapse geometry is confined to one or several triplets of turbidite beds, but never reaches deeper into the cliff than the eroded depth at the foot. We contend that this fracture-limited model of sea-cliff erosion, inferred from the Socoa site dynamics and its peculiar sets of fractures, applies more broadly to other fractured 
cliff contexts, albeit with site specific geometries. The initiation of erosion, the propagation of incremental block release, and the ultimate full failure of the cliff, have each been shown to be fundamentally directly controlled by structure, which remains a vital control in understanding how cliffed coasts have changed in the past and will change in the future.

\section{Keywords}

Sea cliff, erosion, plucking, SfM, photogrammetry, discontinuities, Basque Country, flysch

\section{Introduction}

Sea cliffs are erosional features that demarcate the junction between zones dominated by marine and continental processes (e.g. Young et al., 2021). Critically, their morphology and rate of erosion reflect important variations through time and space. Those variations are explained by local site conditions that dictate the interaction between rock strength (Dornbusch et al., 2008; Sunamura, 1992a), rock structure (Cruslock et al., 2010), and climatic and marine driven processes (Anderson et al., 1999; Caplain et al., 2011; Earlie, 2015; Stephenson and Kirk, 2000; Trenhaile, 2000; Young et al., 2021). Rock properties and environmental conditions in the coastal environments ultimately control erosion rates, define the type of mass movements experiences (Sunamura, 1992a), and control the spatial pattern of erosion across the cliff face (Rosser et al., 2007, 2013).

Surprisingly, unlike other domains of geomorphology where plucking has been largely acknowledged as erosion rate limiting factor (e.g. Scott and Wohl, 2019), rocky coast geomorphology is only just starting to examine this as a meso-scale rock platform erosion process (see notably Naylor and Stephenson, 2010; Regard et al., 2013; 
Buchanan et al., 2020). Here, plucking is understood as the action of removing an integer piece of rock, whatever its size, from the surrounding massif. Whilst much can be learnt from the extensive body of research on rock mass strength and engineering geological perspectives on rock slope failure (e.g. Stead and Wolter, 2015), block plucking by wave action as a cliff erosion rate limiting process is not well established. Plucking of fracture-bounded blocks has been suggested as a control on cliff degradation by Sunamura (1994). Vann Jones et al. (2015) have looked at processes of coastal cliff falls, including temperature fluxes driving block erosion, but to our knowledge, specific investigation of plucking as a process of coastal cliff mass wasting has not been undertaken. The spatio-temporal pattern of cliff failure is known to be controlled by discontinuities (e.g. Hoek and Brown, 1997; Genter et al., 2004), whereby major discontinuities such as faults can control regional coastline planform geometry $\left(10^{4}-10^{5} \mathrm{~m}\right)$ (Giuliano et al., 2013). At the cliff scale $\left(10^{2} \mathrm{~m}\right)$, bulk rock resistance is considered a function of the discontinuities (characteristic spacing of $10^{-3}-10^{2} \mathrm{~m}$ ) in the rock mass (Hoek and Brown, 1997; Selby, 1980).

Cliff erosion has conventionally been reduced to an assessment of cliff top retreat (Letortu et al., 2014), acknowledging that cliff top erosion results from the sum of many events that play out on the cliff face below. This framing is inherited from when cliff recession could only be carried out with cadastral maps and nadir looking aerial photography) (e.g. Moses and Robinson, 2011; Costa et al., 2019).

Terrestrial laser scanning and SFM-photogrammetry more recently helped document cliff face mass wasting phenomena, their size, frequency (e.g. Dewez et al., 2007, 2013; Lim et al., 2010), location (e.g. Rohmer and Dewez, 2013; Earlie et al., 2015; Letortu et al., 2015; Lim et al., 2010; Vann Jones et al., 2015) and effect on the cliff top (e.g. Dewez et al., 2007; Letortu et al., 2015; Young et al., 2009). With shorter intervals 
between surveys and increasing spatial resolution, smaller failures can be captured in response to specific events or conditions, enabling a closer association between erosion and driving factors to be described (Williams et al., 2018). Forensic analysis of erosion scars (de Vilder et al. 2017) further assigned the control of individual fractures and rock bridges as delimiting factors on block detachment. However, to demonstrate the control of fractures on the location, size and timing of detachment requires extended periods of repeated observation often over extensive areas (Benjamin et al., 2020), such that anticipating future rockfall location has remained an open challenge.

Instead, research into cliff collapse hazard assessment has progressed in a different direction. Although cliff failure may appear random over short periods of time, it has been widely demonstrated that erosion via rockfall consistently adheres to volume frequency distributions that exhibit a negative power law form (Barlow et al., 2012; Brunetti et al., 2009; Dewez et al., 2013; Stark and Guzzetti, 2009). Attempts at determining the negative exponent of this relationship from empirical scar inventories resulted in a spread ranging - 0.4 to -1.1 (e.g. Dussauge-Peisser et al., 2002; Williams et al., 2018). Diverging exponent values may arise from a fundamental temporal bias of observation (Williams et al., 2018), where longer measurement campaign intervals lead to amalgamate the volumes from adjacent scars into a single larger rockfall. More recently, Hantz et al (2020) attempted to link exponent variations to the rock structure through Hoek and Brown's (1997) geological strength index (GSI). Fractures, which delimit blocks, influence the value of the exponent by pre-defining detachment volume. Intact and massive rocks (at cliff height scale) rarely produce rockfall and if so, they tend to be large detachments. This derives small exponents as low as -0.3 . Disintegrated massifs can generate -1.1 exponent values, and intermediate GSI indices ("blocky" to "blocky disturbed") derive probabilistic rockfall in the intermediate 
range of exponent from -0.5 to -0.9 (Hantz et al., 2020). Fundamentally, rockfall probability and volume frequency scaling is linked to rock fracturing and its spatial frequency.

Most empirical rockfall scar inventories are limited in duration, sampling interval, spatial resolution and geological setting, which may make models derived from them unstable (Benjamin et al., 2020). The role of rock type and structure remains still poorly understood, in particular when these conditions are known to be highly variable even over small spatial scales (Benumof et al., 2000). Therefore, in spite of recent significant advances in the understanding of how sea cliffs progressively collapse and retreat, it is still challenging to anticipate the magnitude, timing and location of individual events.

Understanding the spatial and temporal pattern of erosion by rockfall is key in explaining both failure mechanisms and the control of environmental forcing. For example, the common schematic of cyclic cliff erosion, from weakening via notching or caving followed by cantilever failure (Sunamura, 1992a; Dewez et al., 2007; Young and Ashford, 2008; Trenhaile, 2015) remains poorly documented, and so may not be as ubiquitous in driving cliff erosion as has been assumed. Alternative models contend that undercutting does not significantly affect shear stress (Wolters and Müller, 2008). Rosser et al., (2013) observing the spatial pattern of erosion along UK cliffed coasts, noticed an upward progression of failure on complex lithology that was initiated without a need for noticeable notching at the foot, indeed where structure allows, a notch may not form nor may not be needed to destabilize the rock face above. In addition, the cyclic model of erosion (e.g. Sunamura, 1992b; Caplain, 2011) implies a dominance of marine action, whereas subaerial erosion processes have been shown to be as, and if not more, important on other actively eroding cliffs, so these models need reconciling (e.g., Roulland et al., 2019; Young et al., 2021). 
Geomorphological literature in other fields has long recognized discontinuities as being the rate limiting factor of bedrock river and glacial incision contexts (e.g. Scott and Wohl, 2019). Plucking is the processes at stake (Naylor and Stephenson, 2010). To occur, the bedrock must be fractured and here a "fracture" is understood as a generic term to describe any discontinuity in an otherwise continuous rock medium (Selby and Hodder, 1993). These fractures delimit blocks in a rock mass. In Selby and Hodder's (1993), terminology, bedding surfaces and metamorphic foliations resulting from sedimentation are also regarded as "fractures", as well as joints and faults from tectonic stresses. Fractures hold several properties that affect plucking: (i) spacing, that controls the size and hence volume and mass of the intact block, (ii) orientation that guides the propagation of erosion and modulates the ease of block plucking and the ability for block release, and (iii) position with respect to the field of driving forces. Whipple et al. (2000) note that fracture spacing, of these properties, defines the weight of individual blocks and acts as a process threshold. At the block threshold size, plucking may be effective. Above this threshold, and at a volume larger than transport capacity, plucking stops and other morphogenetic processes dominate, such as abrasion and corrosion (Whipple et al., 2000). Whipple et al. (2000) thus contend that fracture spacing is ultimately the rate-limiting factor for bedrock river incision.

Within the plucking process, two intermediate mechanisms interact (see Scott and Wohl, 2019): (i) loosening eases block plucking and export from the rock mass matrix; and (ii) fracture-inducing processes further break the bedrock and perpetuate the mass wasting process. In effect, given the inherently finite dimensions of fractures (Scott and Wohl, 2019), plucking stalls if fracturing stops. This notion of fracture length, also described as persistence in rock mechanics, is a particular property addressed in this here. 
Fracture persistence influences erosion. First, "infinite" fractures affect the whole rock mass and cliff, an extend to length scales over which other key controls begin to vary. At cliff-scale $\left(10^{1}-10^{3} \mathrm{~m}\right)$, faults and stratigraphic contacts are regarded as infinite. Second, there are fractures of "finite" extent that affect only part(s) of the cliff massif under consideration. These include lithology specific jointing of finite scale. These two categories of discontinuities have been shown to control the local spatio-temporal patterns of cliff (e.g. Daigneault, 2001; de Vilder et al., 2017) and shore platform erosion (Buchanan et al., 2020), yet beyond enabling kinematic block release, the specific role of each discontinuity remains difficult to distil. For example, bedding orientation may be important in enabling, focusing and directing plucking, but up to now most monitoring studies have concentrated on only sub-horizontal or gently dipping sedimentary layers (e.g. Naylor and Stephenson, 2010; Lim et al., 2010; Bezerra et al., 2011; Rosser et al., 2013; Buchanan et al., 2020).

To explore the role of discontinuities on the spatio-temporal pattern of cliff evolution this study examines the Socoa cliff in the Basque Country, France. Made of a wellbedded, decimeter-scale $\left(10^{-1} \mathrm{~m}\right)$, sedimentary sequence of Cretaceous turbidites (Mulder et al., 2009), cross-cut by a series of normal and reverse faults, this site offers an interesting specimen of well-expressed structural control on cliff behaviour. While many cliff studies focused on gently dipping sedimentary rocks, at Socoa beds plunge at $40-45^{\circ}$ into the sea, with stratigraphy striking parallel to the shore. Beds of weak to strong sediments are centimeter- to decimeter-thick $\left(10^{-2}\right.$ to $\left.10^{-1} \mathrm{~m}\right)$. Strata-bound joints occur at decimeter-scale $\left(10^{-1} \mathrm{~m}\right)$, steep sets of normal and inverse faults cut the massif with $10^{1}-10^{2}$-meter-spacing in approximately cross-shore directions.

We combine field observations, Structure-from-Motion photogrammetry monitoring over 5.7 years and analysis of historical patterns of retreat measured from aerial 
photographs covering 54 years, to explore and document (1) the spatio-temporal pattern of erosion; (2) the association between erosion pattern and the discontinuities; and, (3) how results from Socoa contribute to explain rock control on coastal cliff erosion.
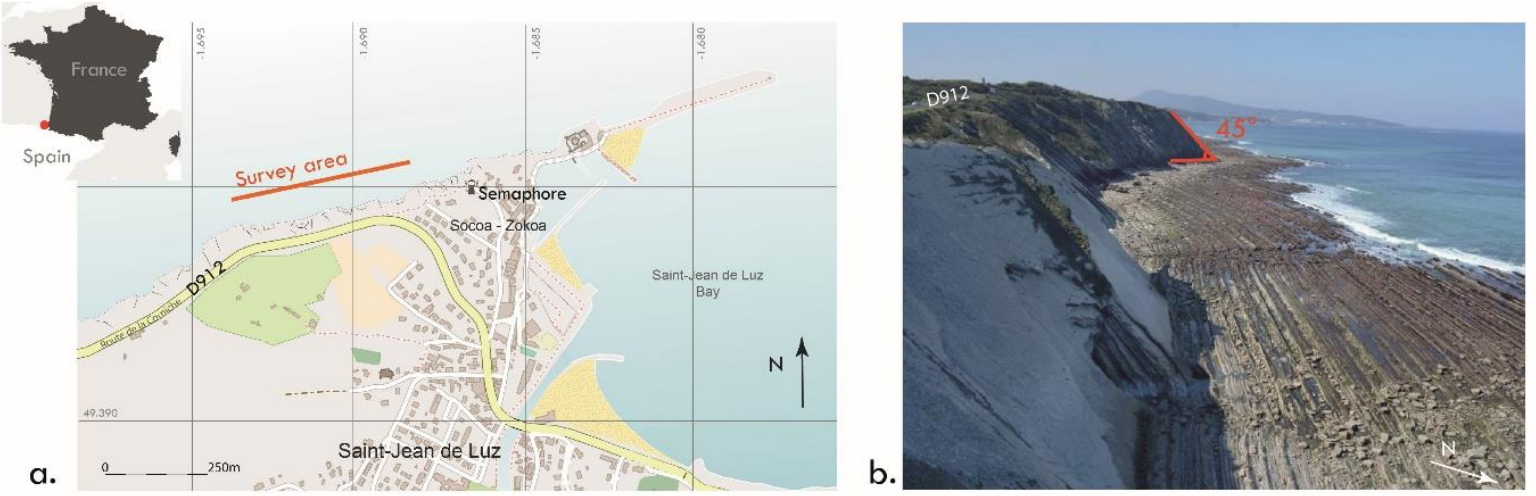

c.
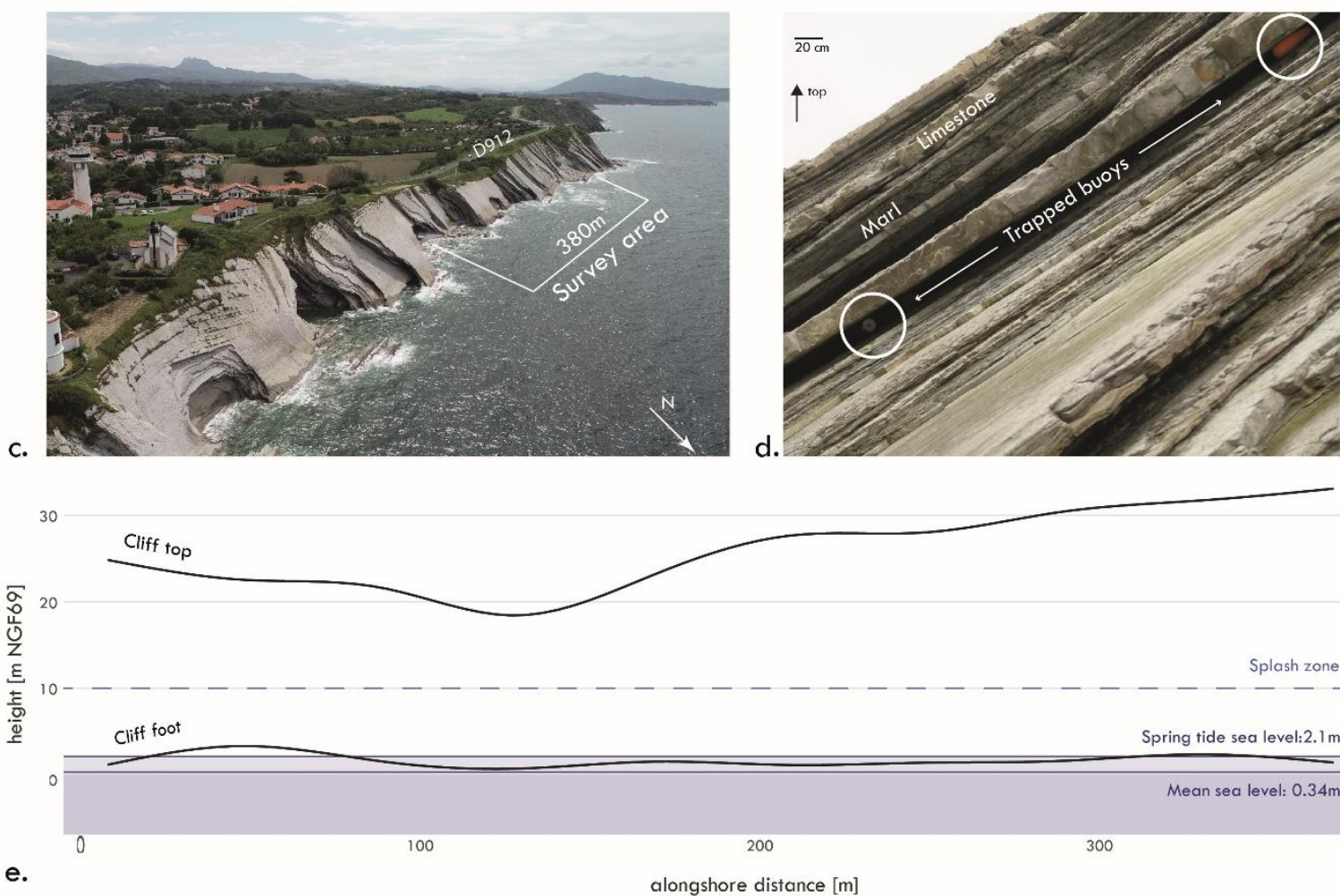

Figure 1: Site location and characteristics. a). The Socoa cliff is located in French Basque Country, West of Saint-Jean de Luz bay and above the D912 touristic road. b). Side view of the monoclonal Socoa flysch sequence, taken during low tide. c). Aerial view of Socoa cliff, photograph 19 June 2019 by L'Avion Jaune for EZPONDA project, during high tide. d). Close-up photograph of structurally defined edges, where two buoys are trapped in a deeply eroded marl strata between two limestone strata. e.) Variation of cliff top and foot height alongshore (smoothed), and sea level (mean sea level, highest spring tide level, splash zone). 


\section{Site setting}

\section{Geology, geomorphology and geometry}

The Basque Country is located on the Atlantic coast, across the French-Spanish border. The coastline is rocky with cliffs in the region reaching locally 80 masl. The Socoa Cliff, the focus of this study, is located west of Saint-Jean de Luz bay, along the $400 \mathrm{~m}$ coastal frontage followed by the D912 road. The scenic views make this a touristic hot spot and conversely a section of high concern for coastal risks managers. Cliff elevation ranges from $21 \mathrm{~m}$ to $32 \mathrm{~m}\left(10^{1} \mathrm{~m}\right)$, above mean sea level (Figure 1). The cliff and shore platform expose the so-called Flysch marno-calcaire de Socoa, i.e. marl and limestone Flysch formation, of Santonian age (Upper Cretaceous) (Razin, 1989; Mulder et al., 2009). The age of this formation is similar to the widely studied receding chalk cliffs bounding the English Channel (Mortimore et al., 2004; Mortimore, 2012), yet Socoa's flysch formations include intercalations of harder rocks, being located in the foothills of the Pyrenees, and the tectonic fabric is far more prevalent.

The sedimentary sequence is composed of successions of deep-sea turbidites (Razin, 1989; Mulder et al., 2009). At this site however, only the last three terms of the expected five of a typical turbiditic Bouma sequence are present (see Mulder et al., 2009): term C (coarse sand to fine silt graded hummocky cross-stratified-like bed), term D (laminated calcareous silts) and $E$ (argillaceous marls). The abnormal lack of terms A and B from the Bouma sequence is considered by Mulder et al. (2009) and explained by the distal position of the cliff site with respect to the original feeding canyons. This repeating sequence makes it a predictable stratigraphic pattern, from which the location of layers with distinct mechanical properties can be anticipated. 
Each turbiditic record (terms $C$ to $E$ ) is several decimeters $\left(10^{-1}-10^{0} \mathrm{~m}\right)$ thick (Figure 2), when measured across exposures on the cliff (see below). The transect shown here crossed 16 turbidite sequences within $5.57 \mathrm{~m}$ of stratigraphic thickness. Term C-D-E sequences averaged $34.8 \pm 19.5 \mathrm{~cm}$, while the more easily identifiable terms $C$ were $5.9 \pm 3.9 \mathrm{~cm}$ thick (e.g. Figure 2).

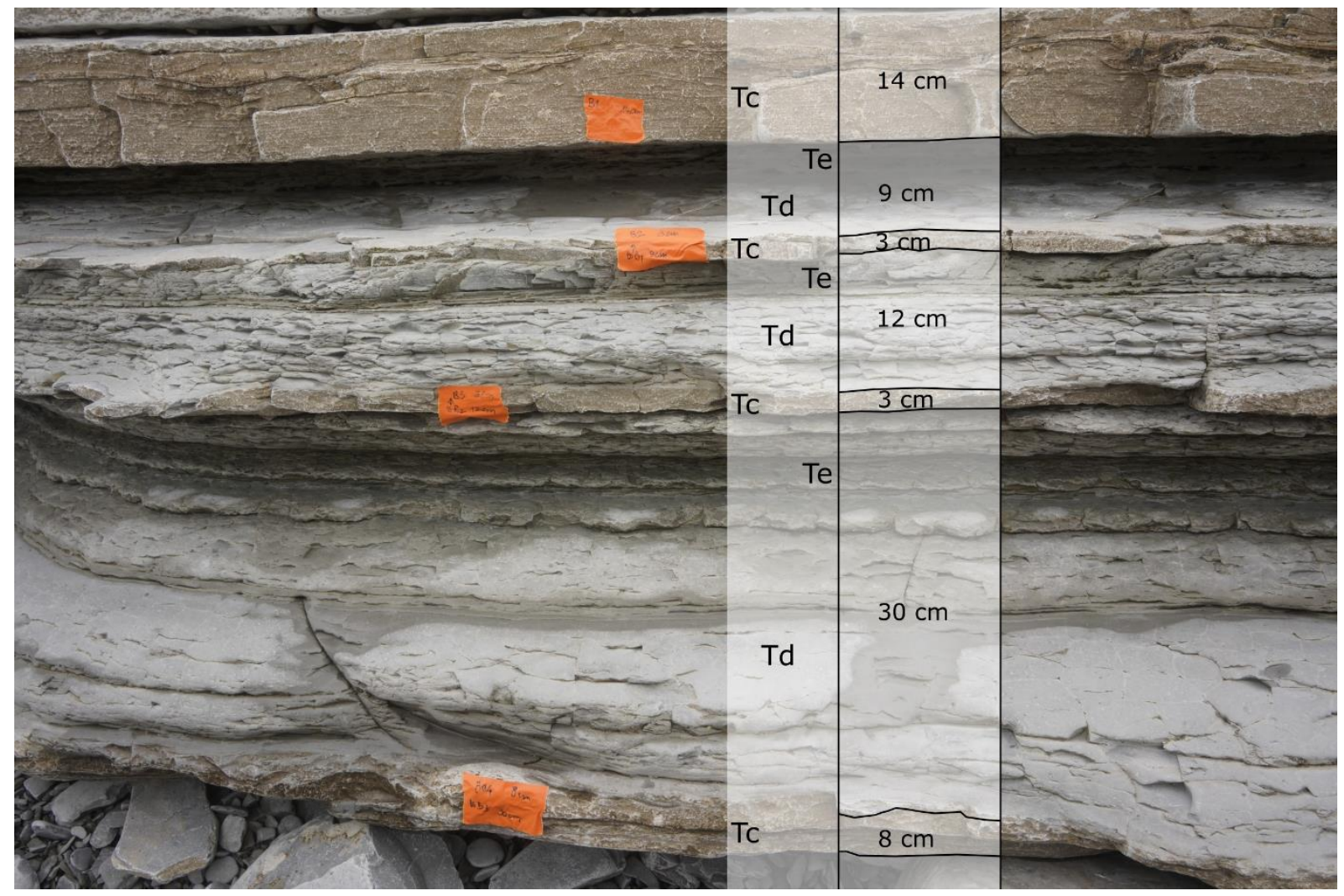

Figure 2: Stratigraphic section through several turbiditic terms encountered in the heart of concavity \#5 (see below). Turbidite Bouma sequences are normally made of five terms. Here, given the distal position of the cliff site deposit only terms $C, D$ and $E$ are present (notations Tc, Td and Td). Each term is centimeter to decimeter thick. The orange-brown, wavy structure and prominent morphology make terms $C$ easily identifiable. They grade into term $D$, finely laminated calcitic silts. Both qualify as medium-strong (R3) to strong rock (R4) mass strength grade of Hoek \& Brown (1997). Terms E, made of argillaceous marls, form centimeter-wide, millimeter-thick platelets, are weak $(R 2)$ to very weak $(R 1)$ layers, depressed. Stratigraphic contacts between terms are clear mechanical limits. We regard them as "fractures" according to Selby and Hodder (1993). 
In terms of rock mass strength, the classification scheme of Hoek and Brown (1997) was applied in the field. Term C beds, calcarenites with cross-stratification-like structures, qualify as Medium Strong (R3) to Strong (R4) rock mass strength. Term D beds, laminated calcareous silts, rate as Medium Strong (R3) to Strong (R4). Both formations needed several hammer blows to chip. Incidentally, this characterization is consistent with a preliminary compressive strength test, $96 \mathrm{MPa}$, performed on a single plug sample (Victor Okumko, Univ. Pau-Pays de l'Adour, pers. comm. November 2019). Term $E$ beds only reach grade R1-R2 and qualify as Very Weak to Weak. They crumble under a firm blow and can be peeled with a pocketknife. Rock mass strength of term $E$ beds are even lower, to reach grade R0 (Extremely Weak) where accessible at the top of the cliff. We observed this situation in early March 2020 after a period of $155 \mathrm{~mm}$ of rain in the 14 preceding days recorded at MeteoFrance weather station ID $64189001,1.2 \mathrm{~km}$ to the east. The wet clay of term E had become plastic under the fingertip and could be rolled into thin boudins. This observation implies that the calcitic matrix that usually strengthens term E beds had previously been dissolved and was not in the consolidated state visible at beach level.

The macroscopic rock mass strength sequence is reflected in the foreshore and cliff morphology as a succession of salient (terms C and D) or depressed beds (terms E) (Figure 1 and Figure 2).

The contacts between the terms are very sharp and can indeed be regarded as "fractures" in the sense of Selby and Hodder (1993). At the scale of the site, we consider that these contact surfaces as globally planar, with local broad curvature of shallow amplitude. They have an infinite lateral persistence reaching the cliff top. Along these sharp stratigraphic contacts, beds are very often mechanically decoupled (Figure 2). 
Tectonically, the sedimentary sequence has been affected by Pyrenean N-S compression since the mid-Eocene, and is now part of a $70^{\circ} \mathrm{N}$-trending inland anticline fold. The seaward limb dips $45^{\circ}$ towards $N 345^{\circ}$ E parallel to the coast as a monocline (Razin, 1989; Mulder et al., 2009). The studied cliff section cross-cuts a ca. $60 \mathrm{~m}$ thick stratigraphic section, from the oldest landward beds exhibited inside the deepest accessible cliff toe caves, to the youngest beds on the most seaward cliff foot sections. In addition to the dominant tilt, regional tectonics are reflected in the cliff fabric. In the surveyed section, we observe three fault families: (i) 3 normal faults dipping $\sim 72^{\circ}$ towards $\sim 257^{\circ}$ (Set 1 on Figure 3, e.g. Figure 4), (ii) 2 reverse faults dipping $\sim 36^{\circ}$ towards $140^{\circ}$ (Set 2 on Figure 3), and (iii) a fault with undetermined kinematic dipping $45^{\circ}$ towards $310^{\circ}$ (Set 3 on Figure 3 ). These individual faults traverse the coastal platform and cut the entire cliff. At the scale of the cliff $\left(10^{1}-10^{3} \mathrm{~m}\right)$, these faults can be regarded as "infinite" fractures.

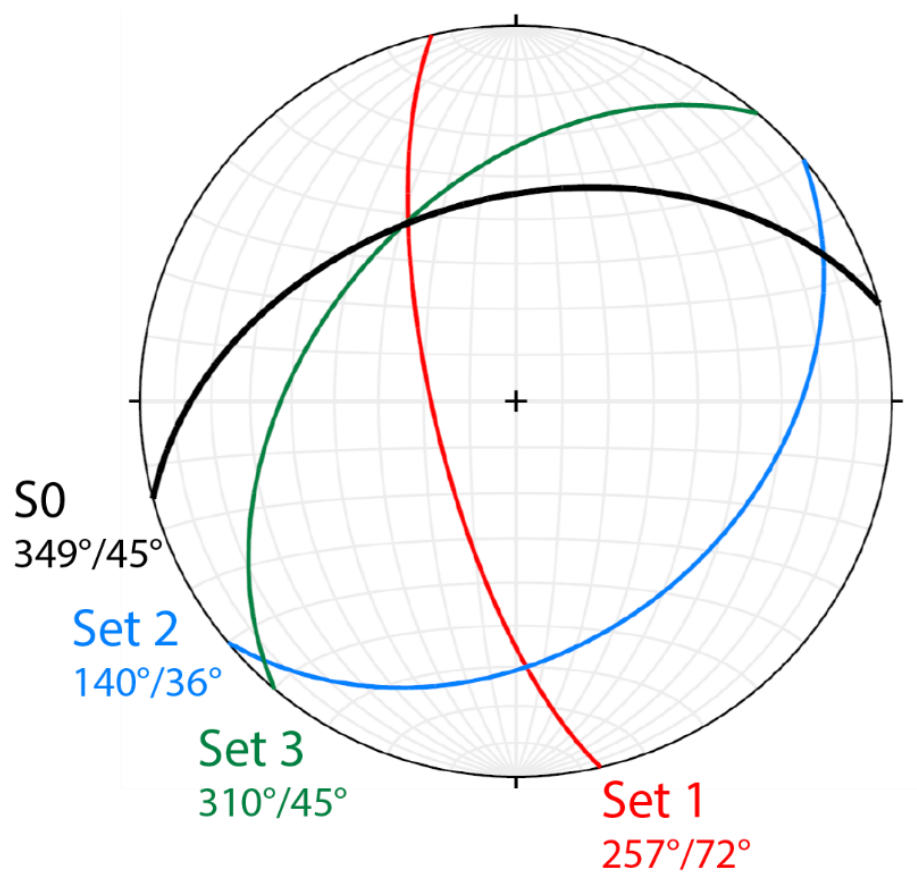

Figure 3: Stereograph of the orientation (dip direction/plunge) of the three sets of faults observed and stratification (SO). 
Finite fractures are also hosted in the flysch, including: (i) a primary bed-normal stratabound joint sets trending NE-SW, dipping to the SE (noted J1 on Figure 4 and Figure 5) ; (ii) a secondary bed-normal strata-bound joint set trending NW-SE and dipping SW which joins primary fractures in relay from one fracture to the next (noted J2 on Figure 4 and Figure 5); and (iii) a polygonal, centimeter-scale-spacing fracture sets expressed in the carbonated muds of term E beds (Figure 5). This last polygonal fracture set accommodates what we describe below as elliptical depression morphologies.

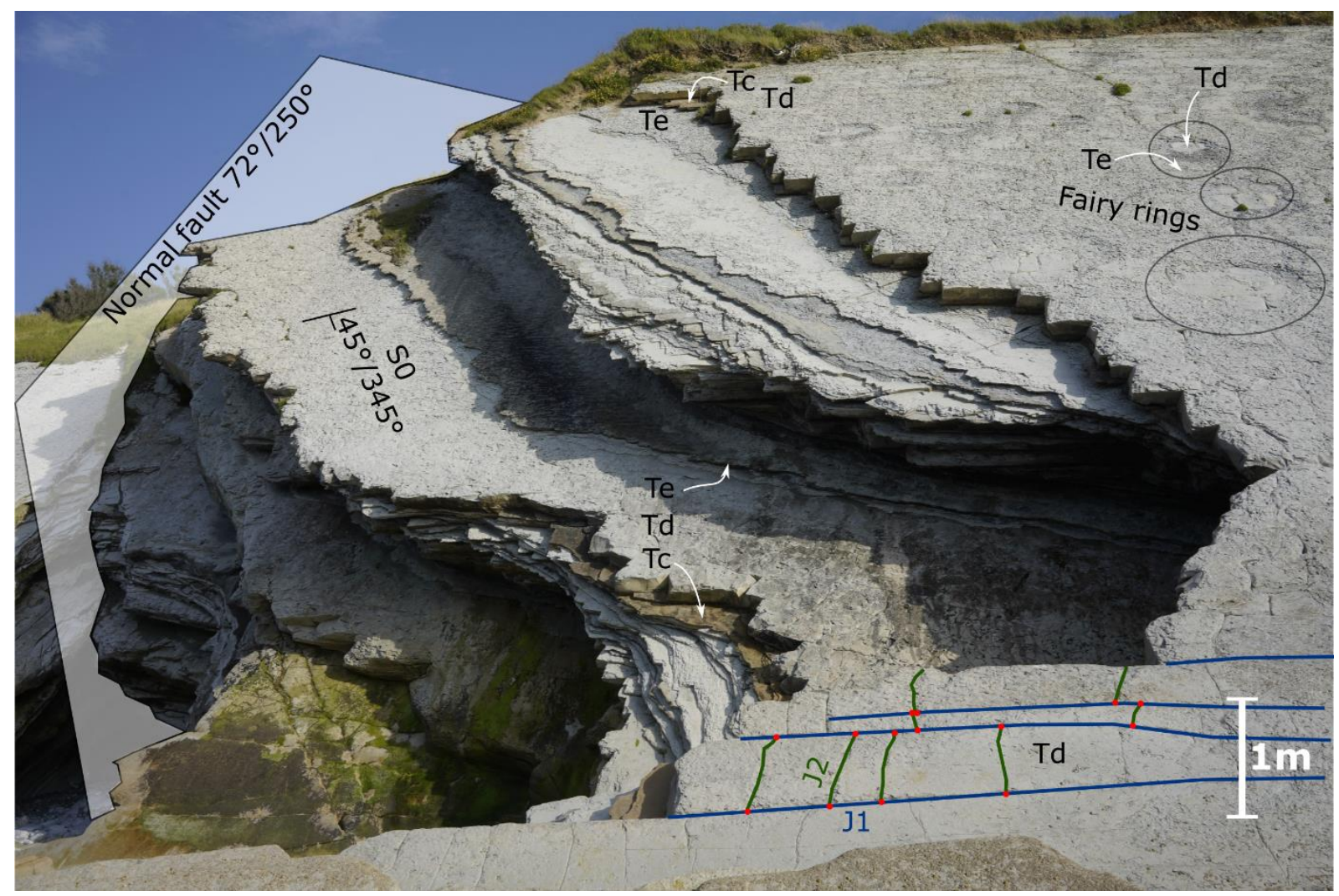

Figure 4: Range of "fractures" observable on the cliff. The normal fault to the left is at the heart of concavity \#3 (see below). Stratigraphic contacts between terms are expressed as large sliding plane. Blue joints (J1) are primary joints have length of several meters. Green joints (J2) have more limited persistence and come abut primary $J 1$ joints. A few joints connections are highlighted in red. The jagged edge of beds $T d$ demonstrates the multi-decimeters width and length of detachable blocks. Thinner, centimeter-widths $\left(10^{-2}-10^{-1} \mathrm{~m}\right)$ and lengths blocks of Tc beds are more finely jagged along the edge. Te centimeter-scale particles of weak to very weak argillaceous marls locally depart in circular pattern to reveal the underlying harder Td bed. 


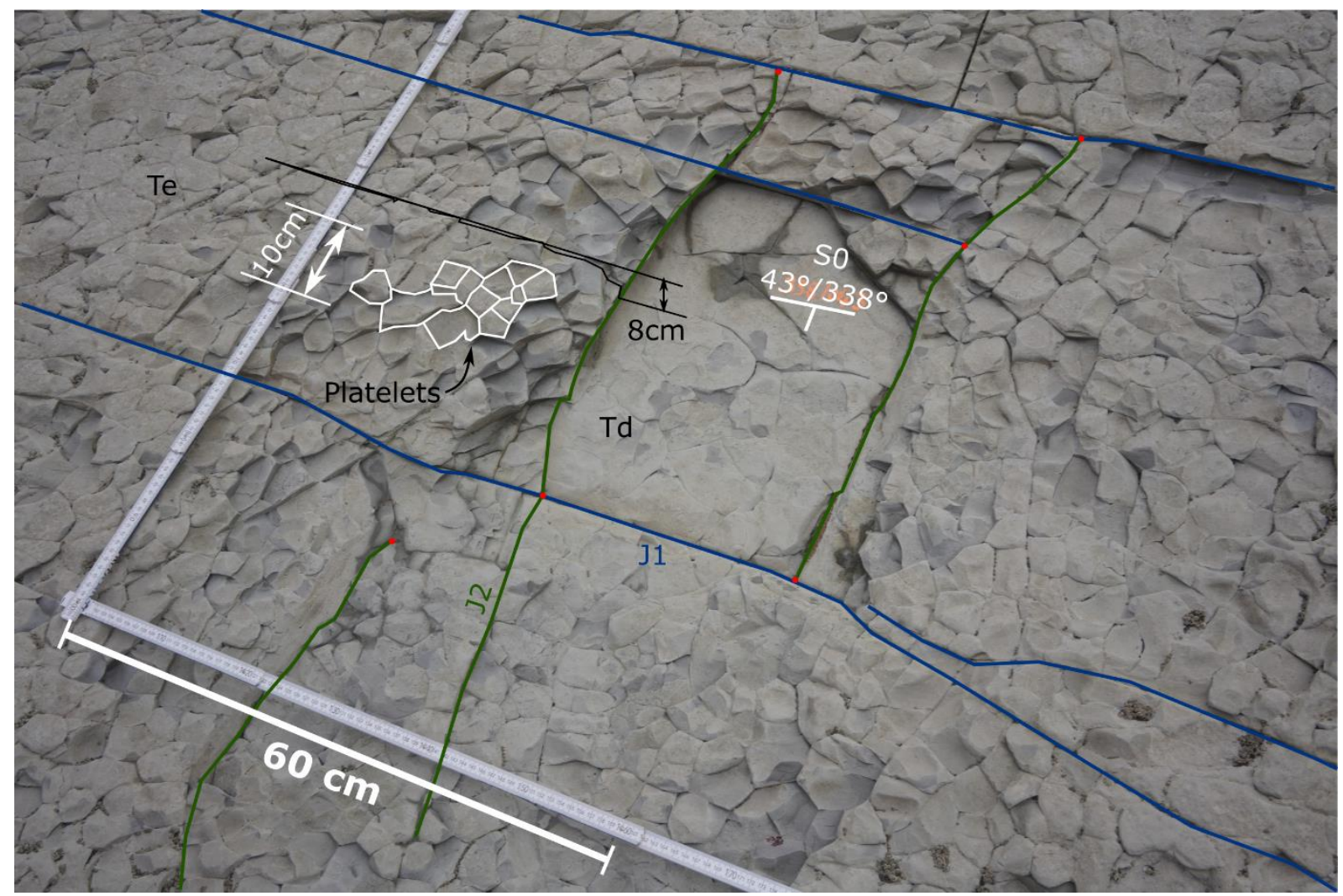

Figure 5: Details of term E (noted Te) and term D (noted Td) surface occurring in the middle of a cliff slab, within tide reach (note the dark limpets in the lower right corner). This is a close-up view of an elliptical depression morphology (see below). Term $D$ top surface shines through, 8 centimeters below, where term $E$ platelets have departed. Term $D$ and $E$ are both affected by joint sets $\mathrm{J} 1$ (left to right blue lines) and $\mathrm{J} 2$ (bottom to top green lines) with contacts highlighted as red dots. Joints, understood as "fractures", cut blocks with multi-decimeter edge lengths. By contrast, term E displays a characteristic multi-centimeter polygonal pattern enabling the detachment of particles only a few millimeters thick that conditions the micro-topography of the surface.

The spacing of strata-bound joints is controlled by the thickness of the mechanical units (e.g. Faÿ-Gomord et al., 2018). This spacing between joints is several times the thickness of the mechanical units. A mechanical unit may encompass several beds at once or just equate to a single term. Typical spacing observed in the field between primary joints is several decimeters $\left(10^{-1}-10^{0} \mathrm{~m}\right.$; e.g. Figure 4 and Figure 5$)$, and even possibly more than $1 \mathrm{~m}$, for hard and thick term $\mathrm{D}$ beds. Thinner term $\mathrm{C}$ beds are more 
frequently fractured at decimeter spacing $\left(10^{-1} \mathrm{~m}\right.$, Figure 4$)$. Weaker term-E beds exhibit multi-centimeter $\left(10^{-2} \mathrm{~m}\right)$ joint spacing that detach as platelets (Figure 5).

The shore platform gently slopes seaward with a mean slope of $1.87^{\circ}$, extending up to $500 \mathrm{~m}$ from the cliff toe during low tides (Maillet, 2014). The platform morphology is rough, with hard flysch beds standing proud by $0.32 \pm 0.50 \mathrm{~m}$ above eroded weaker beds. In Sunamura's classification (Sunamura, 1992a), this shore platform is considered 'type A', because it is not delimited by a sudden seaward drop. The sedimentary cover along the cliff foot comprises only a few lose rock blocks with small ephemeral deposits of sand and gravels, suggesting that blocks detached from the cliff are quickly removed by the sea and do not protect the cliff foot from wave action.

The cliff face exhibits specific morphologies that reflect erosion. The most prominent landforms are concavities, widest at the cliff foot (Figure 1, described by Aubié et al. (2009)), with varied shapes and dimensions. Along the flanks of these concavities, term $C$ and term $D$ bed edges protrude, and term $E$ beds are recessed by decimeters and sometimes meters $\left(10^{-1}-10^{\circ} \mathrm{m}\right.$ ) below the most salient bed edge (Figure 1 and Figure 2).

The annual monitoring surveyed a coastal section of $380 \mathrm{~m}$, over which the cliff height varies between 21 and $32 \mathrm{~m}$, representing a cliff surface area of ca. $13,000 \mathrm{~m}^{2}$. The cliff foot elevation above the terrestrial NGF (Nivellement Général de la France, the French Terrestrial reference elevation datum), reference frame (mean sea level is at $0.34 \mathrm{~m}$ ) varies from $0.48 \mathrm{~m}$ to $2.10 \mathrm{~m}$. The terrestrial datum is $2.18 \mathrm{~m}$ above the marine datum corresponding to the lowest astronomical tide. This means that the cliff foot sits between $2.66 \mathrm{~m}$ and $4.27 \mathrm{~m}$ with respect to the marine datum. The variation of the cliff 
top and foot elevations within the site, and their relation with sea level, are shown in Figure 1e (SHOM, 2016).

\section{Weather and wave climate}

The temperate oceanic climate (Cfb), on the Köppen Geiger classification (Peel et al., 2007) at Socoa presents one of the highest annual rainfall totals in France. Mean annual cumulated rainfall is $1500 \mathrm{~mm} / \mathrm{yr}$, corresponding to on average 140 days of rain per year. Monthly-averaged annual temperature ranges from $10.9^{\circ} \mathrm{C}$ to $18.5^{\circ} \mathrm{C}$. There are on average 11 days of frost per year, when the temperature remains constantly below $0^{\circ} \mathrm{C}$ for 24 hours. All climatic data is summarized from the Socoa semaphore station for 1981-2010 (Météo-France, station n 64189001).

The tidal regime is semi-diurnal with a mean spring tidal range of $4 \mathrm{~m}$ and a maximum astronomical tidal range of $4.93 \mathrm{~m}$ (from SHOM, 2017, p. 59). Swells come mainly from W-NW, with an obliquity of about $25^{\circ}$ southwest of the cliff-normal direction. Mean significant wave height is $1.5 \mathrm{~m}$, with a peak period of $9.6 \mathrm{~s}$ (Abadie et al., 2005). The mean sea level is $0.34 \mathrm{~m} \mathrm{NGF}$. The cliff toe elevation is inundated between middle and high tide. During high spring tide, when the still water level is $2.1 \mathrm{~m} \mathrm{NGF}$, swash climbs the cliff face and can frequently reach $10 \mathrm{~m} \mathrm{NGF}$ (visually checked, e.g. Figure 1.e).

\section{Previous studies}

The "Observatoire de la Côte Aquitaine" (OCA) has responsibility for monitoring coastal evolution. In 2009, Aubié et al. (2009), from OCA, compared cliff top position based on georefenced but not photogrammetrically orthorectified aerial photographs from 1954 and 2008. Within the geometric uncertainties of the technique, a cliff top retreat rate of ca. $100 \mathrm{~mm} / \mathrm{yr}$ was proposed for the Socoa Cliff (Aubié et al., 2011). Furthermore, OCA identified the presence of sea caves, or concavities at the cliff toe, 
as critical in driving cliff instability (Aubié et al., 2009, 2011). A quantification of shore platform erosion due to bioerosion by urchins was estimated as $0.17 \mathrm{~mm} / \mathrm{yr}$ above the depth of -5 m NGF (Regard et al., 2017).

\section{Data capture}

\section{Cliff top retreat from archive aerial photographs}

Here, we reuse the same set of aerial photos as analyzed by Aubié et al., (2011) (IGNFrance https://remonterletemps.ign.fr/), and orthorectify the imagery to assess the longer term rates of cliff top retreat. The images include: five black and white aerial photographs shot on 01 July 1954 (at 1/25000), and thirteen colour photographs of 23 July 2008 (native digital photographs at $72 \mathrm{~cm} / \mathrm{pix}$ ). By contrast to previous processing, Structure-from-Motion (SfM) photogrammetry was used in order to co-register and orthorectify the photographs. SfM processing was performed with Agisoft Photoscan 1.4.2 (build 6205) in July 2018 following the procedure published more recently by Riquelme et al. (2019) and Rault et al. (2020).

Relative camera orientation (alignment) was performed on both photo sets as distinct "chunks". Absolute orientation was computed using the intersection with planimetric Lambert-93 coordinates (EPSG:2154) for mapped features along the cliff top road with coordinates retrieved from IGN's web mapping portal https://geoportail.gouv.fr. These features were chosen from flat terrain at places that have remained unchanged between both image dates, as visually controlled on linked displays of the current ("Photographies aériennes") and historic orthophotographic coverages ("Photographies aériennes historiques 1950-1965") of https://remonterletemps.ign.fr/. As our focus is on measuring change, selecting consistent control point locations from both image dates, which ensured that co-registration was precise through time, even 
if the absolute location (i.e. accuracy) is less reliable, according to the principles described in Rault et al. (2020). For the 1954 imagery, 3 points served as control and 4 points as independent checks. For 2008, 6 points served as control and 4 as checks points. Additional control points were added in the Untxin River valley to improve elevation control in the center of the dataset.

After relative and absolute orientation, an "ultra-high quality" dense point cloud (sensu Photoscan) was generated for both data sets (1954: 21.5 Mpts; 2008: 54.6 Mpts). A DEM and an orthomosaic at the best possible resolution (1954: $0.93 \mathrm{~m} / \mathrm{pix} ; 2008: 0.72$ $\mathrm{m} / \mathrm{pix}$ ) were then produced. From these orthomosaics the cliff top, as the sharp break in slope separating the cliff face from the hinterland, was manually digitized for both epochs. The retreat rate was estimated using the area method (e.g. Letortu, 2013) whereby the retreat area is delimited by the 1954 and 2008 cliff tops. This area integrates cliff top positional change along the cliff line to provide an averaged retreat. This method is less subject to sampling issues associated with the transect procedure of Digital Shoreline Analysis System (Himmelstoss et al., 2018).

\section{Cliff face ground-based SfM from shore platform}

Topographic changes on the cliff face were monitored using ground-based SfM photogrammetry, using photographs shot from the platform at low tide. Although the exact photograph positions were not marked on the platform (prohibited due to the site EU Natura 2000 designation), we followed recognizable along-shore-trending rock strata to maintain a consistent revisit journey, year after year. Because the cliff is not perfectly linear, the camera cliff distance was reduced to follow the mid-level recess upon the cliff face and decreasing cliff height to the East (Figure 1.d). Six SfM photographic campaigns were shot between 16 June 2011 and 03 February 2017 (Table 1), approximately one per year, spanning in total 2070 days. Camera, lens and 
processing characteristics (Table 1) are provided to comply with the recommendations of James et al., (2019). Whilst camera hardware changed through the course of the study, improving point spacing on cliff from 26 to $5 \mathrm{~mm}$, all clouds were subsampled to achieve a constant resolution of $1 \mathrm{pt} / 25 \mathrm{~mm}$ for all surveys. The initial survey shot on 16 June 2011 included referenced targets positioned with a Leica EDM total station with centimeter precision $\left(10^{-1} \mathrm{~m}\right)$. Camera georeferencing (i.e. absolute global positioning) was achieved with a Garmin 62CSX GPS with meter-scale accuracy. Again, as our focus was change, not absolute locational precision, this accuracy bracket does not affect the change detection procedure within our study. All point clouds were processed in local coordinates in respect to the first survey, and further matched relatively to one another with Iterative Closest Point cloud-to-cloud registration.

The "one panorama each step" SfM acquisition strategy (Wenzel et al., 2013) was used to design the survey. Three to five divergent photographs were taken at each station (or "step", Wenzel et al. (2013)), spaced approximately 15 to $20 \mathrm{~m}$ from one another alongshore. Cliff to camera distance varied from $25 \mathrm{~m}$ to $80 \mathrm{~m}$ (Figure 6). To assess the expected theoretical precision depth (Wenzel et al., 2013), a mean camera to cliff distance of $50 \mathrm{~m}$ is assumed in Table 1.

Points clouds were computed using Agisoft Photoscan (1.2.4 version). Dense clouds were extracted in "Ultra-High" mode (as recommended for 3D point cloud change detection on cliff faces in Dewez et al., (2016)) with a mild filtering. Before computing differences, point clouds were further registered to the first survey (June 2011) using the automatic registration algorithm in Trimble Real Works (10.1). 
Table 1: Structure-from-Motion cliff monitoring campaign characteristics.

\begin{tabular}{|c|c|c|c|c|c|c|c|c|}
\hline Date & $\begin{array}{l}\text { Came } \\
\text { ra }\end{array}$ & $\begin{array}{l}\text { Pixel } \\
\text { resolution } \\
{\left[I^{*} h\right] \text { and }} \\
{[\text { Mpix] }}\end{array}$ & $\begin{array}{l}\text { Sensor } \\
\text { dimensio } \\
n[\mathrm{~mm}]\end{array}$ & $\begin{array}{l}\text { Photosit } \\
\text { e } \\
\text { physical } \\
\text { size }[\mu \mathrm{m}]\end{array}$ & Lens & $\begin{array}{l}\text { Geotagge } \\
r\end{array}$ & $\begin{array}{l}\text { Use } \\
\text { of } \\
\text { contr } \\
\text { ol } \\
\text { point }\end{array}$ & $\begin{array}{l}\text { Expected depth } \\
\text { precision }[\mathrm{m}]\end{array}$ \\
\hline $2011 / 06 / 16$ & $\begin{array}{l}\text { Canon } \\
\text { 30D }\end{array}$ & $\begin{array}{l}3504 x \\
2336 \\
{[8 \text { Mpix] }}\end{array}$ & $22.5 \times 15$ & $6.4 \times 6.4$ & $\begin{array}{l}\text { Canon } \\
20 \mathrm{~mm}\end{array}$ & Yes & Yes & 0.018 \\
\hline $2012 / 05 / 06$ & $\begin{array}{l}\text { Nikon } \\
\text { D700 }\end{array}$ & $\begin{array}{l}4928 \mathrm{x} \\
3264 \\
{[16 \text { Mpix] }}\end{array}$ & $\begin{array}{l}23.6 x \\
15.7\end{array}$ & $5.4 \times 4.8$ & $\begin{array}{l}\text { Nikkor } \\
20 \mathrm{~mm}\end{array}$ & Yes & No & 0.013 \\
\hline $2014 / 06 / 17$ & $\begin{array}{l}\text { Nikon } \\
\text { D90 }\end{array}$ & $\begin{array}{l}4288 \mathrm{x} \\
2848 \\
{[12 \mathrm{Mpix}]}\end{array}$ & $23.6 \times 15.8$ & $5.6 \times 5.5$ & $\begin{array}{l}\text { Nikkor } \\
20 \mathrm{~mm}\end{array}$ & Yes & No & 0.015 \\
\hline $2015 / 07 / 30$ & $\begin{array}{l}\text { Nikon } \\
\text { D90 }\end{array}$ & $\begin{array}{l}4288 x \\
2848 \\
{[12 \text { Mpix] }}\end{array}$ & $23.6 \times 15.8$ & $5.6 \times 5.5$ & $\begin{array}{l}\text { Nikon } \\
18-55\end{array}$ & No & No & 0.017 \\
\hline $2016 / 04 / 06$ & $\begin{array}{l}\text { Nikon } \\
\text { D5500 }\end{array}$ & $\begin{array}{l}6000 x \\
4000 \\
{[24 \text { Mpix] }}\end{array}$ & $\begin{array}{l}23.5 x \\
15.6\end{array}$ & $3.9 \times 3.9$ & $\begin{array}{l}\text { Nikon } \\
18-55\end{array}$ & Yes & No & 0.012 \\
\hline $2017 / 02 / 13$ & $\begin{array}{l}\text { Nikon } \\
\text { D5500 }\end{array}$ & $\begin{array}{l}6000 x \\
4000 \\
{[24 \text { Mpix] }}\end{array}$ & $\begin{array}{l}23.5 x \\
15.6\end{array}$ & $3.9 \times 3.9$ & $\begin{array}{l}\text { Nikon } \\
18-55\end{array}$ & Yes & No & 0.009 \\
\hline
\end{tabular}

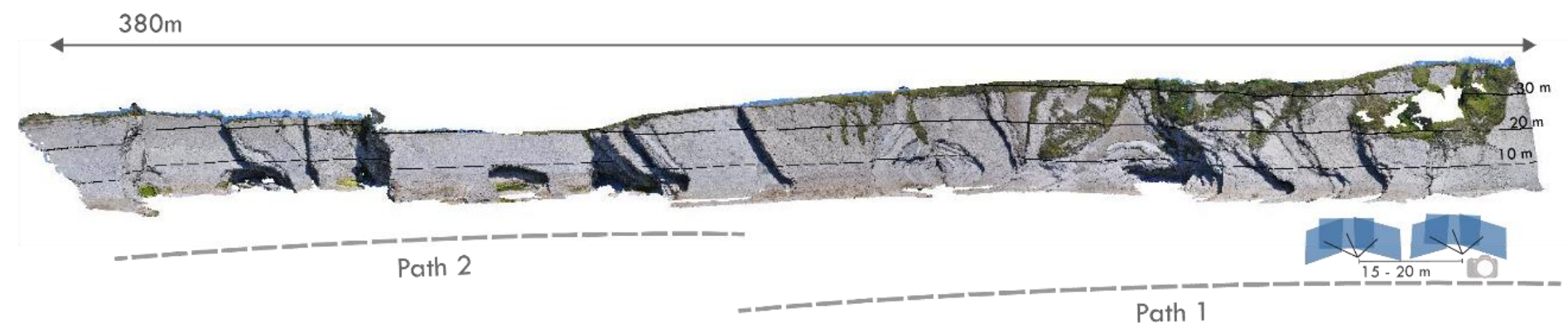

Figure 6: Acquisition method for SFM monitoring and 3D point cloud. Two consistent paths were followed for each epoch and the "one panorama each step" acquisition strategy (Wenzel et al., 2013) was used to take photographs.

In order to analyse cliff change and evolution, Cloud-to-Cloud differences were computed with the M3C2 algorithm (Lague et al., 2013) in CloudCompare (GirardeauMontaut, 2011). Considering the stratified structure of the cliff, the "normal scale" was fixed perpendicular to the stratification (dip of $45^{\circ}$, in a direction $\mathrm{N} 349^{\circ} \mathrm{E}$ ) in order to estimate cliff recession. The "projection scale" was set to $0.1 \mathrm{~m}$ and differences between clouds were computed on core points with a spatial step of $0.075 \mathrm{~m}$ (see: 
Lague et al., 2013). After computing epoch-to-epoch differences, post-processing corrected difference values affected by a series of systematic and non-systematic errors (Figure 7).

\section{Raw M3C2 signal (raster)}

a.

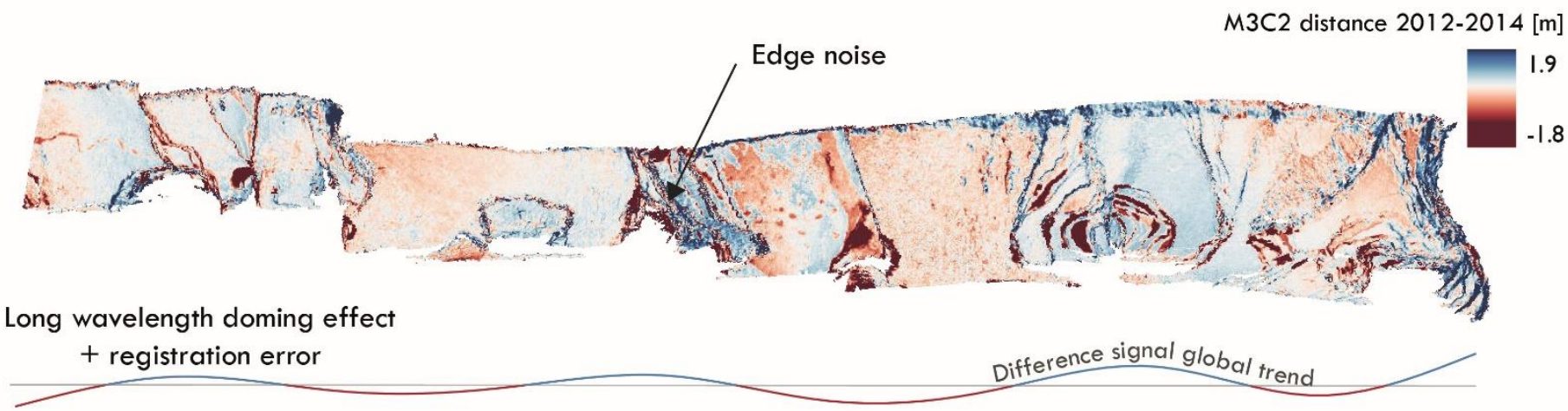

Removal of non-erosion signals

\section{Erosion scar polygons}

I

Eroded volume [m3]

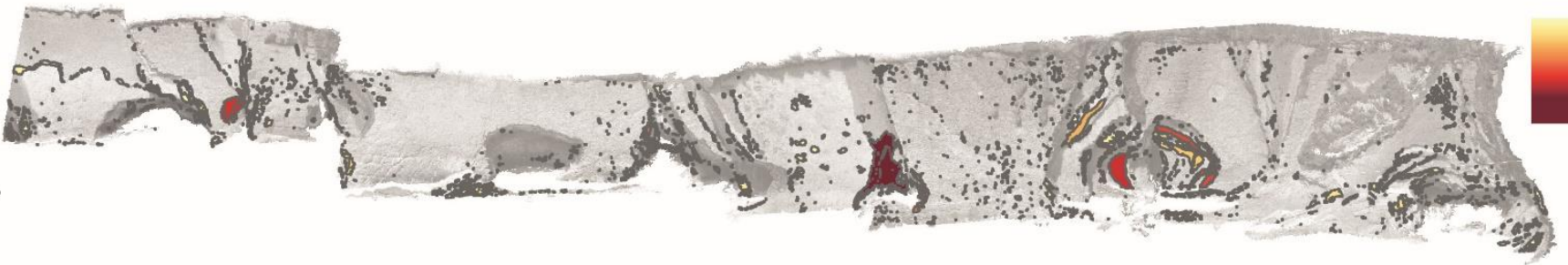

Figure 7: Signal cleaning: from raw point cloud to eroded blocks database. a). Raw M3C2 differences $(m)$. Erosion signal is visible as others spurious signals: noise at edges, long wavelength dooming effect and registration error that were removed. b). Final scars shapefile, each scar is isolated and contains information about erosion and scar geometry.

It was apparent that most of the difference signal was located around topographic edges or convexities in the point cloud (Figure 7.a). Based on repeated field observations, strata edges stand out as the most active erosion zones, though these features are also affected by erroneous measurements. Indeed, these are the most complicated areas to reconstruct in 3D, due in particular to frequent occlusion and 
variable level of description by the data. It was therefore necessary to find a reproducible method to discriminate actual edge erosion from poor surface reconstruction spurious difference. To do this, we used a random forest binary classification (Breiman, 2001) to identify change at each point in the cloud as either "real" or "erroneous" erosion. The classification was based on the numerical outputs of M3C2 algorithm, including standard deviation, distance uncertainty, M3C2 distance, and number of points used to compute differences. We added the volumetric density of points within 0.05-, 0.1 - and 0.5 -m-radius spheres. The learning data set was constructed manually based on photographic interpretation of true versus false erosion (see example in Figure 8.a.). The learning set was divided into training (70\%) and test sets $(30 \%)$. The random forest achieved an area under the curve of 0.98 when run on the test dataset. Ranking discriminant parameters identified the standard deviation of M3C2 points as the most discriminant parameter with a threshold of $0.01 \mathrm{~m}$ (see Figure 8.b.). Applying this threshold to the test dataset retained $80.6 \%$ of true eroded points, while simultaneously removing $93 \%$ of false positives. Application of the random forest procedure proved efficient both to select the most discriminant parameter, and identify objectively change threshold values. This was the first difference post-processing segmentation applied to isolate meaningful erosion.

The second non-erosion signal was non-systematic and was related to the lack of wellknown control targets during photogrammetric surveys. Despite acquiring oblique photographs to strengthen the photogrammetric network, as explicitly recommended by Wenzel et al., (2013), the point clouds were affected by a "doming" effect (visible on Figure 8). This long wavelength deformation, here observed at length scales of ca. $50 \mathrm{~m}$ with $<5 \mathrm{~cm}$ in amplitude, was described in Dewez et al., (2013) and James and Robson, (2014). To model and correct for this global deformation defect, we 
interpolated the long wavelength deformation trend using an inverse distance weighting (IDW) model on a 2D difference raster of the data. The IDW parameters were: (i) $15 \mathrm{~m}$ radius given the long ranging, alongshore wavelength of the signal, and (ii) 0.01 as the weighting exponent. A small exponent gives nearly equal weight to remote and close neighbors and controls the desired smoothing signal. This global difference trend interpolated across the difference field is applied to the difference signal. This spatially variable bias correction procedure is acceptable as photogrammetric models may not always reach perfect rigidity due to imperfect camera parameter inversion (James and Robson, 2014) and can be considered akin to designing a spatially variable erosion threshold value.
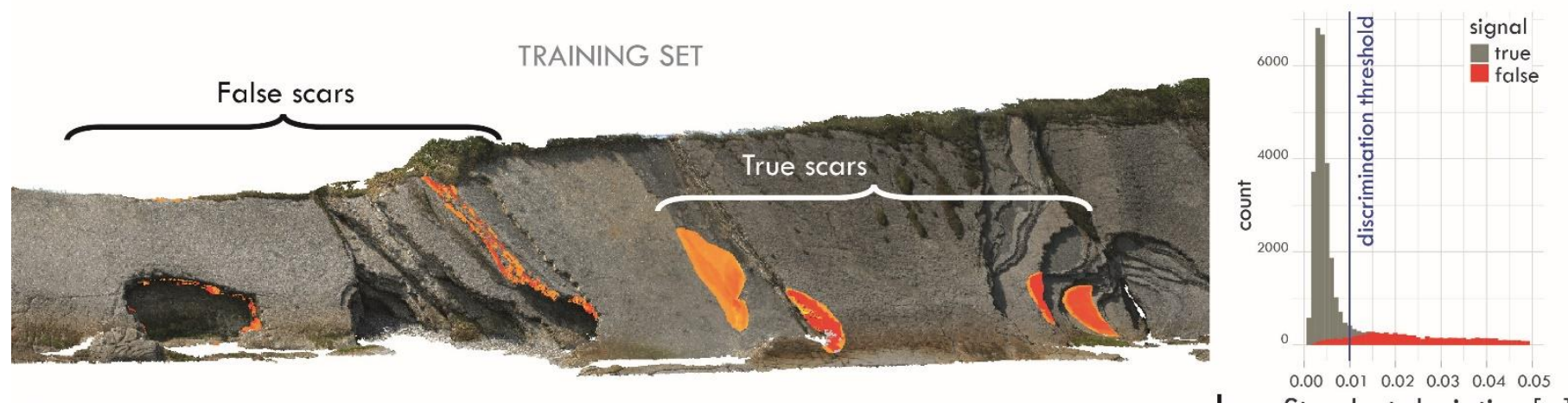

a.

b. Standart deviation $[\mathrm{m}]$

Figure 8: Detection of non-systematic error at cliff edge. A. Presentation of point cloud with "true" erosion scars and "erroneous" ones due to poor reconstruction of cliff edges. $B$. Histogram of standard deviation of points for M3C2 computation, categorized by true and false erosion signal.

The last signal removed was a systematic error due to suboptimal cloud to cloud registration. To remove this, a detection threshold was computed for each epoch based on point dispersion along five planar surfaces known to be stable over time (surfaces of $\sim 40 \mathrm{~m}^{2}$ each), following the method proposed by Dewez et al., (2013). The erosion detection threshold was fixed as one percentile of the M3C2 distance on the reference 
planes. Thresholds values for each epoch are given in Table 2. Values of difference below those thresholds was considered to represent a stable point of the cliff with no discernable change. Values ranged between $-0.064 \mathrm{~m}$ and $-0.023 \mathrm{~m}$, which is similar to rates identified in other studies of rocky coast erosion (Dewez et al., 2013; Giuliano, 2015; Williams et al., 2018).

Table 2: SfM results, with erosion calculated for the Socoa Cliff within each monitored epoch between 2011 and 2017.

\begin{tabular}{|c|c|c|c|c|c|c|}
\hline & $\begin{array}{l}2011- \\
2012\end{array}$ & $\begin{array}{l}2012- \\
2014\end{array}$ & $\begin{array}{l}2014- \\
2015\end{array}$ & $\begin{array}{l}2015- \\
2016\end{array}$ & $\begin{array}{l}2016- \\
2017\end{array}$ & $\begin{array}{l}\text { Sum of } \\
\text { differences } \\
(2011-2017)\end{array}$ \\
\hline Survey time interval [days] & 326 & 773 & 408 & 251 & 321 & 2070 \\
\hline Detection threshold [m] & 0.064 & 0.023 & 0.034 & 0.045 & 0.029 & \\
\hline $\begin{array}{l}\text { Equivalent cliff top recession } \\
\text { rate }[\mathrm{mm} / \mathrm{yr}]\end{array}$ & 1.6 & 4.4 & 2.8 & 3.7 & 2.9 & 3.4 \\
\hline Total eroded volume $\left[\mathrm{m}^{3}\right]$ & 13 & 83.24 & 27.9 & 22.8 & 23 & 170 \\
\hline $\begin{array}{l}\text { Maximum single scar volume } \\
{\left[\mathrm{m}^{3}\right]}\end{array}$ & 2.5 & 6.86 & 3.21 & 2.48 & 6.32 & 6.86 \\
\hline
\end{tabular}

To summarize, the filtering workflow applied to M3C2 raw differences included: (i) At the whole point cloud level, removal of data in the cloud with an $\mathrm{M} 3 \mathrm{C} 2$ standard deviation $>0.01 \mathrm{~m}$ in any epoch; (ii) rasterization of point clouds in elevation view to a $0.15 \mathrm{~m}$ resolution; (iii) modeling of a long wavelength bias using long ranging and nearlinear IDW and recovering the residual signal; (iv) thresholding all pixels with differences smaller than a noise percentile to isolate erosion scars; and (v)Vectorization of of raster scar grids to allow geospatial analysis on spatially segmented polygons. The time-stamped scar polygon layers were compiled into a block scar database of erosion characteristics (mean, minimum, maximum and sum of erosion for all pixels within a scar), and geometrical information (surface, volume, centroid, position). 


\section{Results}

\section{General results}

The mean cliff-top retreat rate estimated from the historical aerial photograph comparison is $10.8 \pm 1.8 \mathrm{~mm} / \mathrm{yr}$ over the 54 years between 1954 and 2008. On the basis of $1: 25,000$ aerial photographs, the cliff top appears to be relatively stable during this period. Conversely, the 5.7 years concurrent with direct observations of the cliff face showed extensive erosion activity, equating to a volume of $\sim 0.33 \mathrm{~m} 3 / \mathrm{m} / \mathrm{yr}$ ( $~ 830$ $\mathrm{kg} / \mathrm{m} / \mathrm{yr}$, assuming a bulk flysch density $\sim 2.5 \mathrm{~g} / \mathrm{cm}^{3}$ ). SfM cliff face monitoring over this period recorded 4,448 single scars accounting for a total volume of $170 \mathrm{~m}^{3}$, and a total scar area of $1,750 \mathrm{~m}^{2}$. This erosion is equivalent to an average annual cliff face recession of $3.4 \mathrm{~mm} / \mathrm{yr}$ ( $\sim 220 \mathrm{~kg} / \mathrm{m} / \mathrm{yr}$ of flysch). Individual scar volumes ranged from $1.45 \times 10^{-3} \mathrm{~m}^{3}$ to $6.86 \mathrm{~m}^{3}\left(10^{-3}-10^{1} \mathrm{~m}^{3}\right)$, with a median of $6.4 \times 10^{-3} \mathrm{~m}^{3}$. Individual scar surface area varied between $6.75 \times 10^{-2} \mathrm{~m}^{2}$ and $81.8 \mathrm{~m}^{2}\left(10^{-2}-10^{3} \mathrm{~m}^{2}\right)$ with a median of $0.11 \mathrm{~m}^{2}$, equivalent to a square of $0.33 \mathrm{~m}$.

The distribution of scar surface versus depth (Figure 9) shows considerable scatter. Some scars exceeded $1 \mathrm{~m}$ depth, even when their surfaces areas were small $\left(0.09 \mathrm{~m}^{2}\right.$ scar, equivalent to a $0.3 \mathrm{~m}$ square). We interpret this surprisingly deep value as a mask removal effect linked to the effectiveness of the 2D change detection method (M3C2 normals were set constant and orthogonal to the stratigraphy). In the foreground, on the right of Figure 4, term $\mathrm{D}$ bed is cut by joint sets $\mathrm{J} 1$ and $\mathrm{J} 2$. This bed is obviously salient in the erosion of a multi-metre deep concavity. If one block along its edge was to be removed, the previously occluded concavity behind would suddenly become visible and included in the change detection. A similar situation is apparent, though with a reduced effect, below the uppermost term $C$ bed of Figure 2. As the term $E$ bed 
is eroded deeply, removing the term C bed would reveal this void behind. So, the scar depths presented in Figure 9 are not just a direct volume loss estimate but rather a time-integrating, erosion measure.

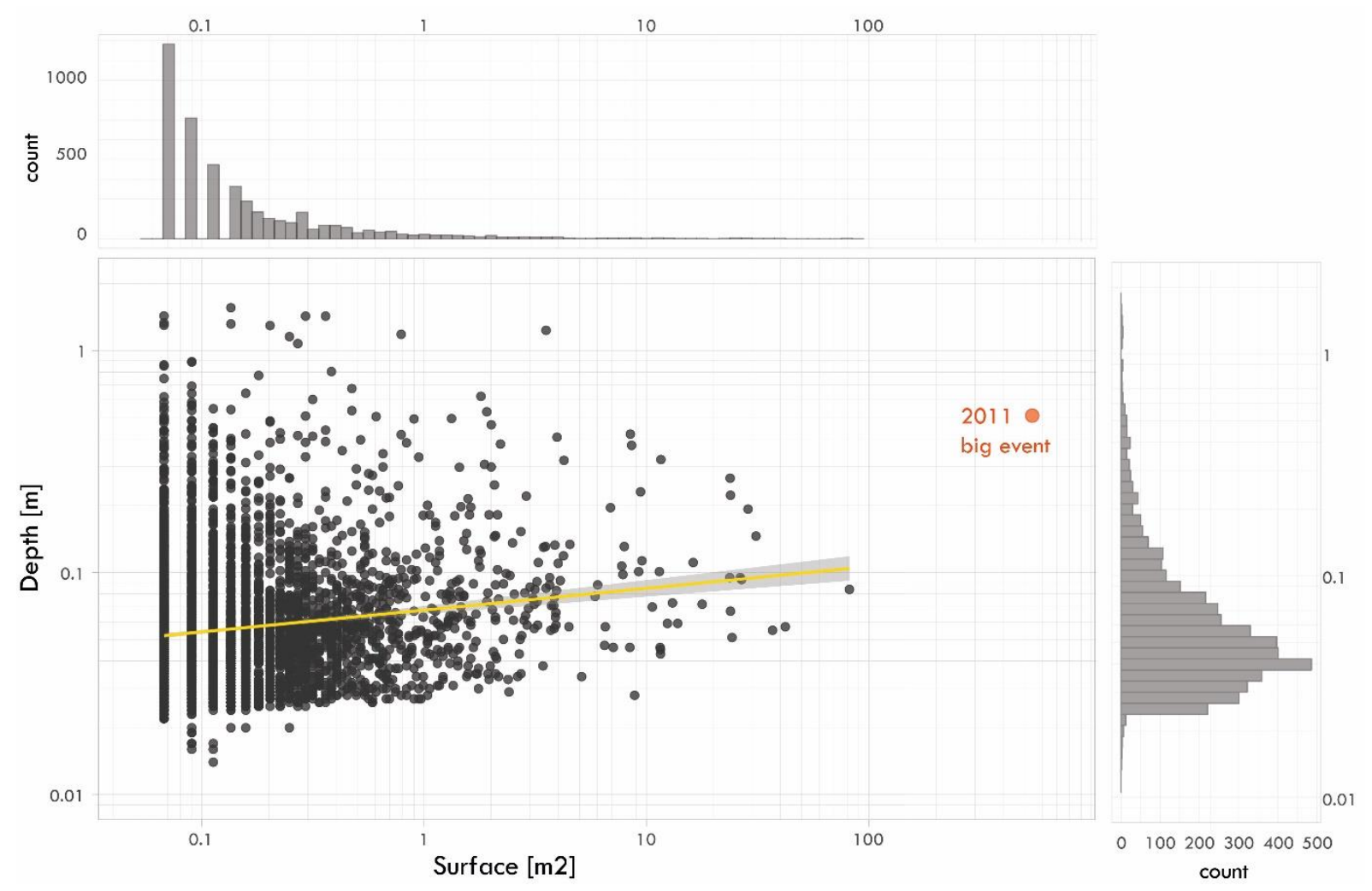

Figure 9: Rockfall scar surface area versus scar depth at the Socoa cliff between 2011 and 2017. Best fit regression line is in yellow, with confidence envelope. Depth mode is $4 \mathrm{~cm}$.

Apart from this occasional over-estimation of erosion depth, Figure 9 shows little dependence between surface area and depth, whereby larger surface area scars do not translate into thicker rock pieces being detached. In other words, scar depth does not scale with surface area and instead, the depth distribution (Figure 9) shows that blocks remove relatively thin rock layers, with $90 \%$ of thicknesses between $0.026 \mathrm{~m}$ and $0.21 \mathrm{~m}\left(10^{-2}-10^{0} \mathrm{~m}\right)$ with a modal depth of $0.04 \mathrm{~m}$. In the field, this range of thicknesses matches single turbidite term (see examples in Figure 2, Figure 4 or Figure 
10). From this, we conclude that stratigraphic contacts indeed play a strong mechanical role in limiting scar depth, irrespective of the surface area involved.

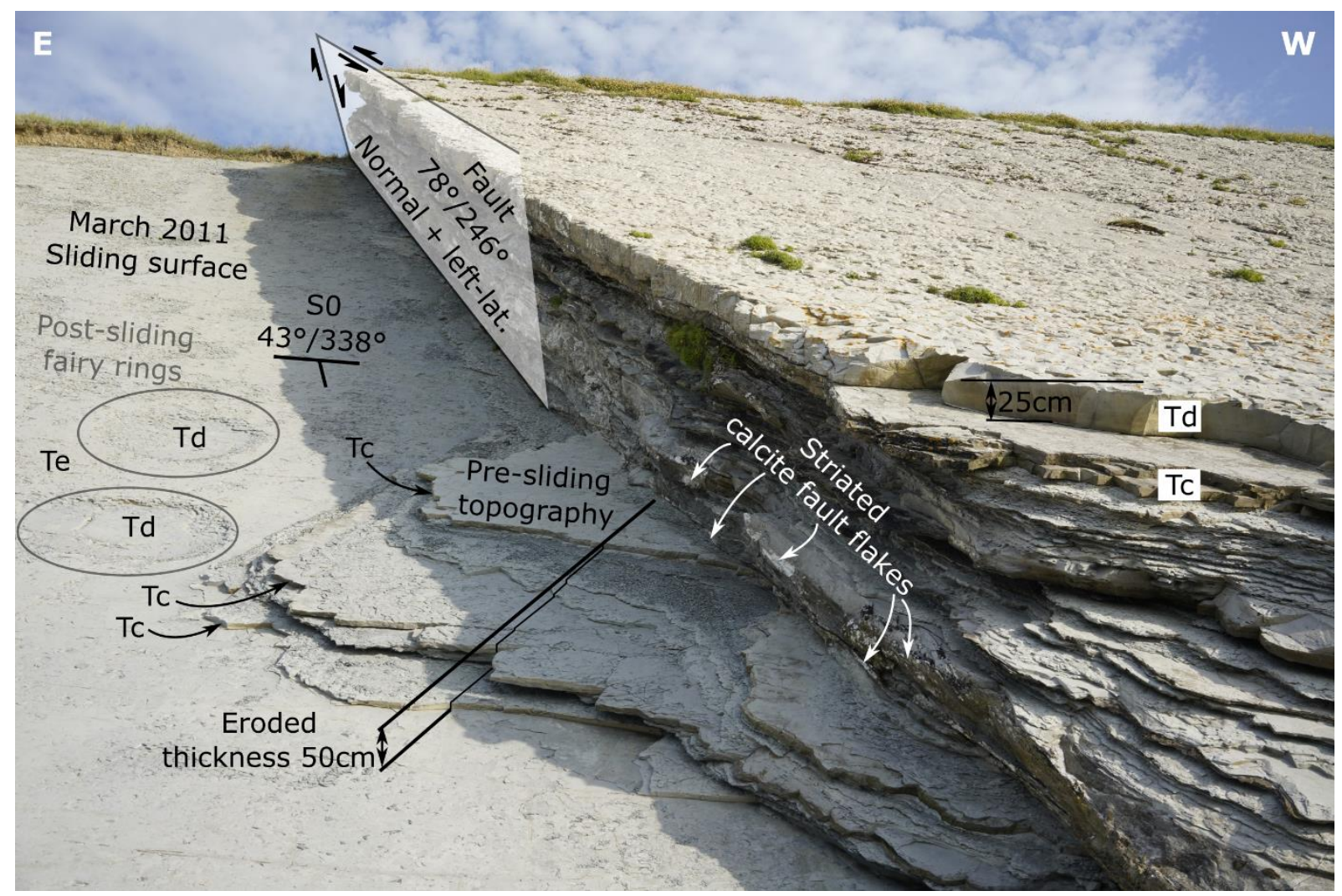

Figure 10: Remaining topography of the eastern compartment of concavity \#4 after the slab collapse that occurred between February and April 2011. The now-disappeared slab slid on a term E bed (notation Te) dipping $43^{\circ}$ towards $338^{\circ}$. The mobilized 50 $\mathrm{cm}$-thick sedimentary stack comprised 3 turbidite sequences as testified by the three $C$ terms remaining in place today (notations Tc). The eastern compartment is delimited to the west by a calcite-filled fault plane (dipping $78^{\circ}$ towards $246^{\circ}$ ) with normal/leftlateral kinematic preserved in striated calcite flakes.

No large event, exceeding $100 \mathrm{~m}^{2}$, affected the entire cliff face to the top during the monitoring period. This observation is likely only a temporal censoring effect. Large rockfalls are known to occur in the monitored section and elsewhere along this coast. For instance, one event occurred on the elliptical depression slab between February and April 2011 (see Figure 10), just prior to this study's monitoring started. The event was identified in photographs taken during field visits that bracket this period. Based 
on this imagery, the slab which fell entrained three turbidite sequences (three terms C to $E$ sequences) across a total thickness of $50 \mathrm{~cm}$ (Figure 10). Sliding occurred on the lowermost argillaceous marl term E exposed at the foot of the slab.

We visually estimated the volume of this rock fall to be ca. $260 \mathrm{~m}^{3}$ (surface of $\sim 520 \mathrm{~m}^{2}$ and a depth of $0.5 \mathrm{~m}$, deduced from the intact residual patch of material on the western side of the slab, Figure 2). This single slab collapse represents more material than the total of $170 \mathrm{~m}^{3}$ observed during the nearly 6 years of SfM monitoring. Such events are infrequent, and no comparable magnitude events were identified at cliff top level within the historical aerial photograph comparison, nor were any diagnostic sediment stacks detected. Moreover, despite the large surface area on the cliff face of this failure, the thickness of the detachment remains moderate and restricted to a few beds, which are barely detectable from $1 / 25,000$ archive photographs.

\section{Spatial and temporal patterns of erosion}

The scar data set suggests that erosion is variable through time (Table 2 and Figure 11). The period 2012 - 2014 was the most active, with an equivalent cliff retreat of $4.4 \mathrm{~mm} / \mathrm{yr}$, whereas $2011-2012$ recorded only $1.6 \mathrm{~mm} / \mathrm{yr}$. Erosion is spatially focused rather than dispersed in all epochs, with a locus of activity at specific sections of the cliff face (Figure 11). Some areas remained unchanged within the bounds of our measurement precision throughout the monitoring period. Considering the cliff profile, the cliff foot (between 0 and $10 \mathrm{~m}$ elevation) is most active, as shown in the erosion distributions (Figure 11). Horizontally, erosion is focused on bed edges, which represent the daylighting of particular sets of discontinuities, most notably around concavities carved into the cliff. These edges are most numerous around these deep concavities, where a depth of several meters of cliff material has been eroded through multiple strata. Erosion scars are typically limited in depth to $\sim 1 \mathrm{~m}$ (Figure 11). Our 
data suggest that rock fall is usually limited to single turbidite terms or stacks of these (e.g. Figure 10). In order to gain insight on the cliff mass wasting process and its relation to fractures, we focus below on two phenomena: the evolution of concavities, and the evolution of term E argillaceous marl beds.

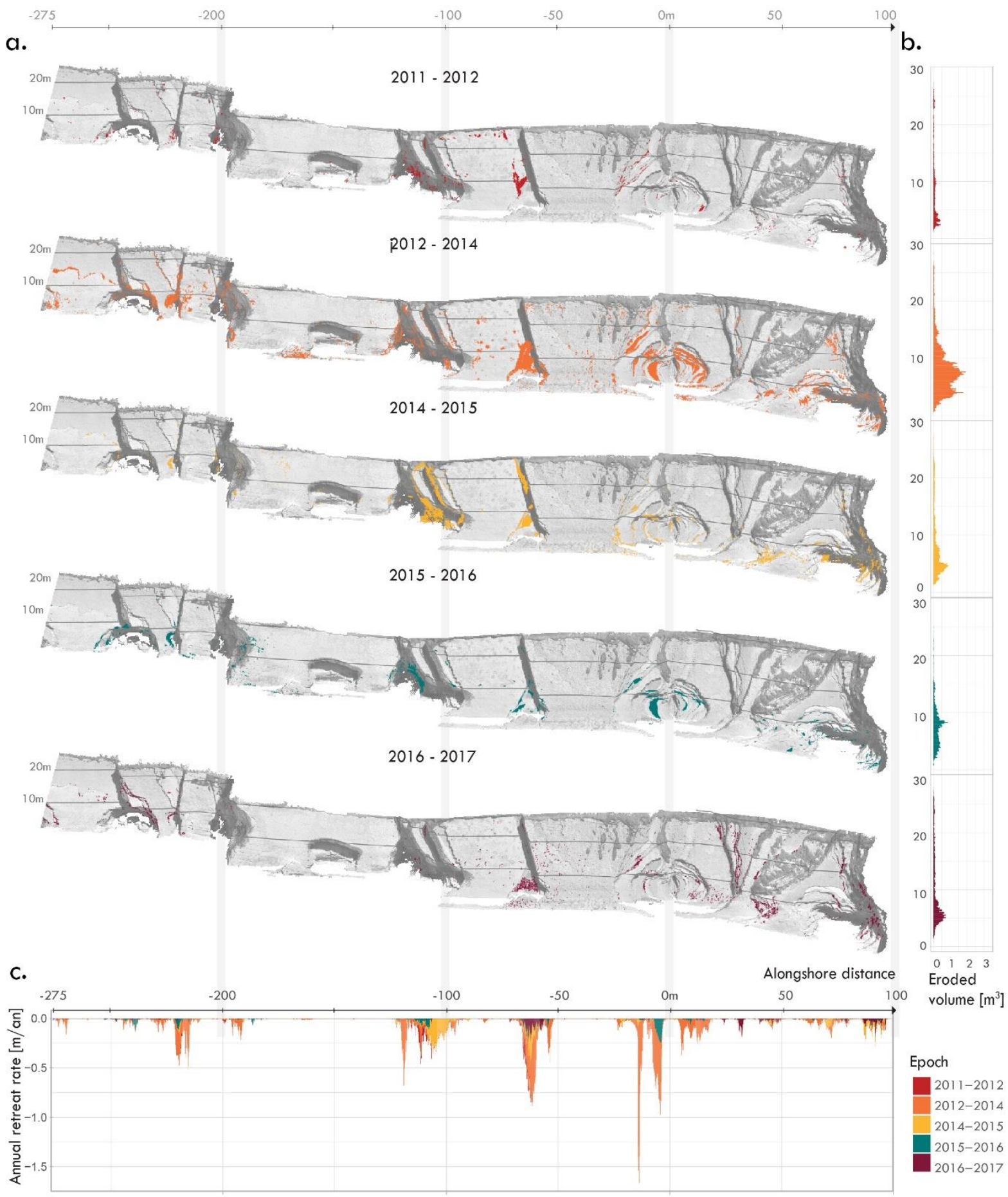


Figure 11: Erosion of Socoa cliff between 2011 and 2017, result of SfM survey. a. colored eroded blocs among cliff face, b. Eroded volume [m3] vs cliff height, c. Alongshore annual retreat rate $[\mathrm{m} / \mathrm{yr}$.

\section{Concavity erosion}

The pronounced concavities are a remarkable feature of the Socoa cliffs, and may provide an insight into the way the cliff erodes and then evolves. The SfM survey highlighted these locations and their vicinity as the most actively eroding points along this cliff section. The five most prominent features of this type are described in Figure 12 and Table 2, where we present geometrical and geomorphological information for each feature. Erosion information, including the number of eroded blocks, total eroded volume, and the erosion rate (eroded volume normalized by surface) is compiled. The concavity set is divided into two: Type A corresponds to concavities at the cliff foot without a fault (for example concavity \#2); Type B corresponds to concavities rooted on a fault, that can be asymmetric (such as concavity \#1 or \#4) or symmetric (concavity \#3 or \#5). Note that strata may be offset by the fault (Table 2).

The five concavities are characterized by higher erosion rates than the rest of the cliff. Although their surface represents only $13 \%$ of the cliff face, they produce $41 \%$ of the total volume eroded $\left(70 \mathrm{~m}^{3}\right)$. This being said, the five concavities show variable block production rates. Concavity \#2 is relatively stable with only $0.6 \mathrm{~m}^{3}$ eroded across a surface area of ca $336 \mathrm{~m}^{2}$ (average erosion depth of $0.0017 \mathrm{~m}$ ), whereas \#4 produced a volume about ten times larger $\left(5.5 \mathrm{~m}^{3}\right)$ for a surface about five times smaller $\left(66 \mathrm{~m}^{2}\right.$, average erosion depth of $0.083 \mathrm{~m}$ ). 


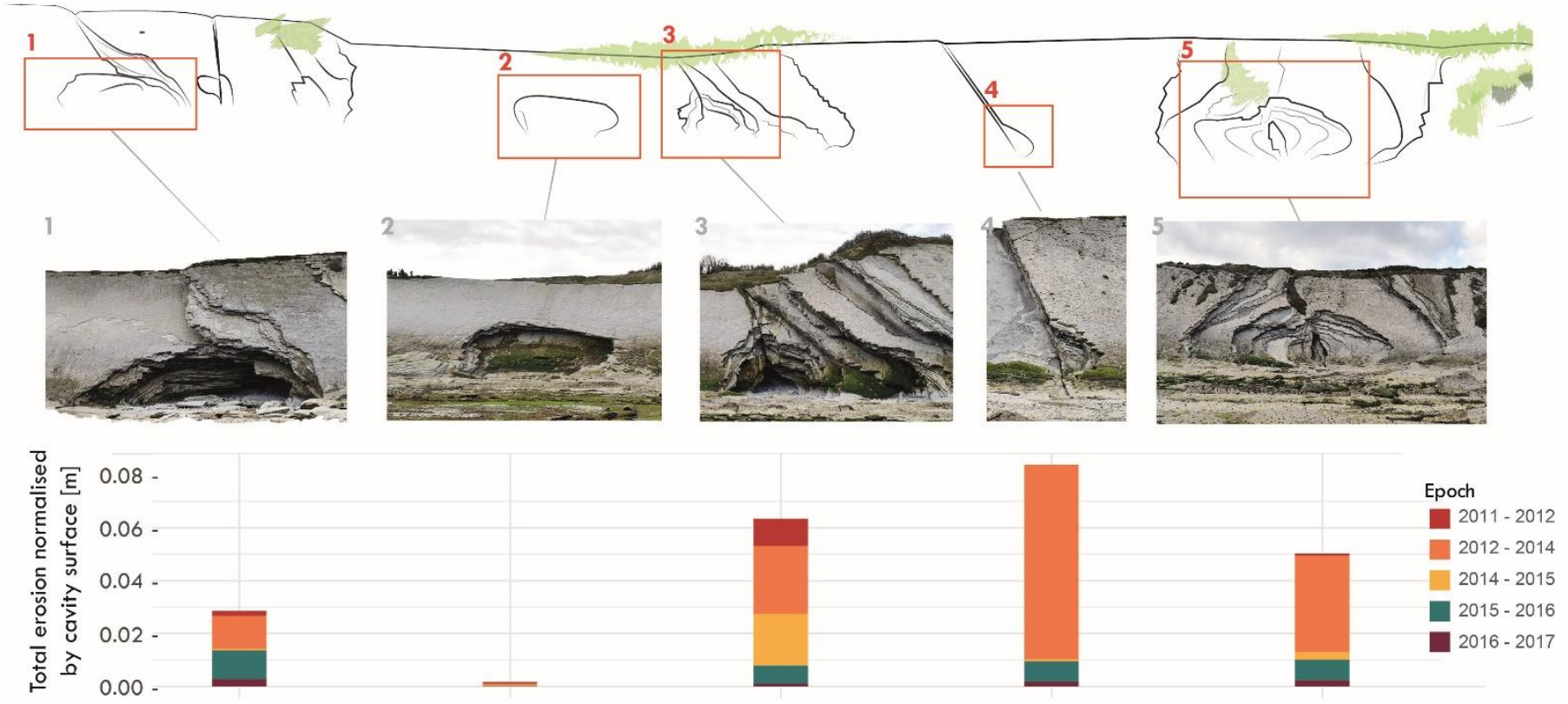

Figure 12: Presentation of 5 concavities we focused on and their total erosion normalized through each concavity surface.

From Table 3, block production appears to be related to the presence of a fault, which promotes the release of blocks. The number of visible edges bounding the concavities increases with the number of scars (Spearmann's rank correlation $=0.75$ ). As is visible on Figure $1 \mathrm{~d}$ and Figure 4, with visible bed edges, corresponding to medium-strong to strong turbidite terms $C$ and $D$, hiding deeply recessed weak to very weak layers of terms E. To allow plucking of stronger blocks, it is likely that a weaker layer must be eroded beforehand. Once the first blocks are detached from the cliff base level, a concavity develops radially and upward (Figure 13). The shape of the concavities then become elliptic rather than circular, indicating that lateral growth of these features is faster than upward growth. 


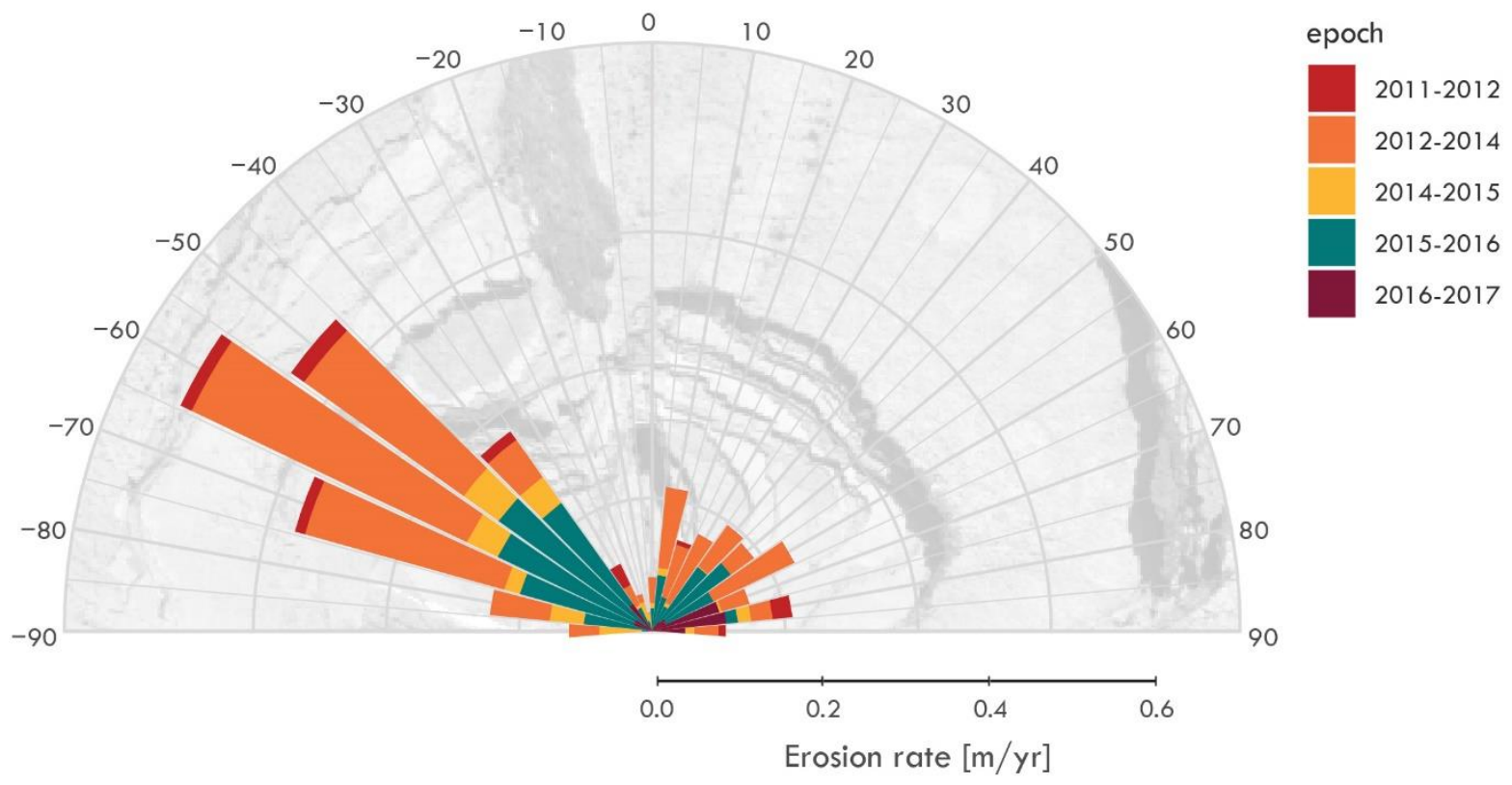

Figure 13: Lateral erosion of concavity \#5. Erosion rate is computed every 10 degrees around concavity center. It is represented on a background greyscale image of the concavity.

Table 3: Morphological and erosional characteristics of five concavities.

\begin{tabular}{|c|c|c|c|c|c|c|}
\hline Concavity \# & 1 & & 2 & 3 & 4 & 5 \\
\hline Concavity type & B & & A & $B$ & B & B \\
\hline $\begin{array}{l}\text { Concavity dimension } L^{*} H \\
{[\mathrm{~m}]}\end{array}$ & $29 * 12$ & & $24 * 14$ & $20 * 18$ & $6 * 11$ & $32 * 23$ \\
\hline Depth [m] & 9 & & 5 & 10 & 4 & 6 \\
\hline Surface $\left[\mathrm{m}^{2}\right]$ & 348 & & 336 & 360 & 66 & 736 \\
\hline Presence of a fault & yes & no & & & yes & yes \\
\hline Fault dip/dip direction & $45^{\circ} / 310^{\circ}$ & - & & $50^{\circ}$ & $78^{\circ} / 246^{\circ}$ & $\begin{array}{l}81^{\circ} / 084^{\circ} \\
65^{\circ} / 268^{\circ}\end{array}$ \\
\hline Kinematics & NA & - & & & $\begin{array}{l}\text { ormal\&left- } \\
\text { lateral }\end{array}$ & $\begin{array}{c}\text { NA } \\
\begin{array}{c}\text { Normal\&left- } \\
\text { lateral }\end{array}\end{array}$ \\
\hline Number of visible edges & 4 & 3 & & & 4 & 16 \\
\hline Number of eroded blocks & 245 & 63 & & & 50 & 458 \\
\hline $\begin{array}{l}\text { Total eroded volume }\left[\mathrm{m}^{3}\right] \\
{[2011-2017]}\end{array}$ & 9.9 & 0.6 & & & 5.5 & 37 \\
\hline $\begin{array}{l}\text { Erosion rate [mm/yr] } \\
\text { (normalized through } \\
\text { concavity's surface) }\end{array}$ & 5.1 & 0.31 & & & 14.9 & 8.9 \\
\hline
\end{tabular}

When no fault is present, as at concavity \#2, sideways and upward erosion is slow and depth expansion ceased. While we cannot say for sure for concavity \#2, a similar "rugby ball-shaped" concavity (visible at the lower left corner of Figure 1c) was 
investigated. Along the eastern side, joints crossed multiple turbidite sequences, but do not extend beyond the bed forming the backwall of the concavity. We contend that concavity \#2 probably formed in a similar manner. The sea quarried through the sedimentary pile along a strata-bound joint until it reached its terminus at depth. Lacking any further prospect of penetration, block plucking only kept occurring laterally along bedding planes, detaching jointed blocks. So here too, the concavity is rooted on and directed along a fracture, albeit a fracture with limited depth and height persistence. When a fault is present, erosion carries on indefinitely inside the rock mass and up cliff, directed by the fault weakness. If the fault dips to one side, fractured edges follow the same trend. When the fault strike is oblique to the stratigraphy, the elongation of the concavity inside the cliff expands obliquely to the stratigraphy. This situation was observed in concavity \#1 (fault $45^{\circ} / 310^{\circ}$, that is $35^{\circ}$ off the stratigraphynormal azimuth) with a deeper penetration of erosion where the fault pierces the back of the concavity than cross-shore.

\section{Elliptical depression erosion}

A second phenomenon of interest has been observed on the surface of turbidite argillaceous marl terms E directly eastward of concavity \#4. This slab was first exposed to weathering between February and April 2011 (Figure 14a) when the undercut material slid downslope. (Figure 14a, b). Elliptical depressions started to form and grow outwards on the newly exposed surface. These depressions which etch the slab surface topography result from the detachment of $2-5 \mathrm{~cm}$ edge-length polygonal rock flakes or platelets $\left(10^{-2} \mathrm{~m}\right.$, visible in Figure 5 and Figure $\left.14 \mathrm{~b}\right)$. Their thickness has a lens-shaped form, typically $3-5 \mathrm{~mm}$ at its thickest $\left(10^{-3} \mathrm{~m}\right)$. One particle would weigh 19 grams with approximate dimensions of $3 \times 5 \times 0.5 \mathrm{~cm}$, and a density of $2.5 \mathrm{~g} / \mathrm{cm}^{3}$. In cross-section, where this elliptical depression-bearing bed can be observed, the 
fracturing pattern already exists. It is therefore not a fracture pattern that emerged when the bed became unloaded and exposed on the cliff face, but rather an exploitation of existing structure.

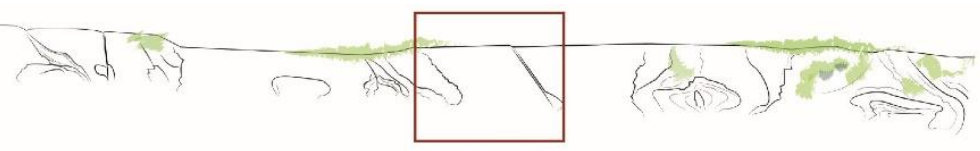

a.
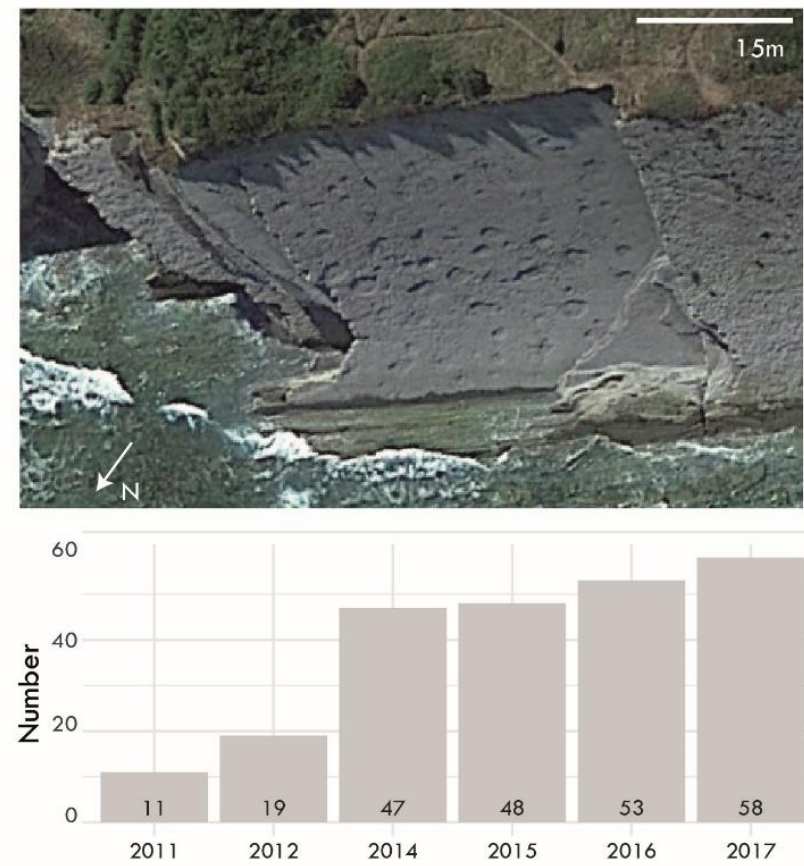

b.
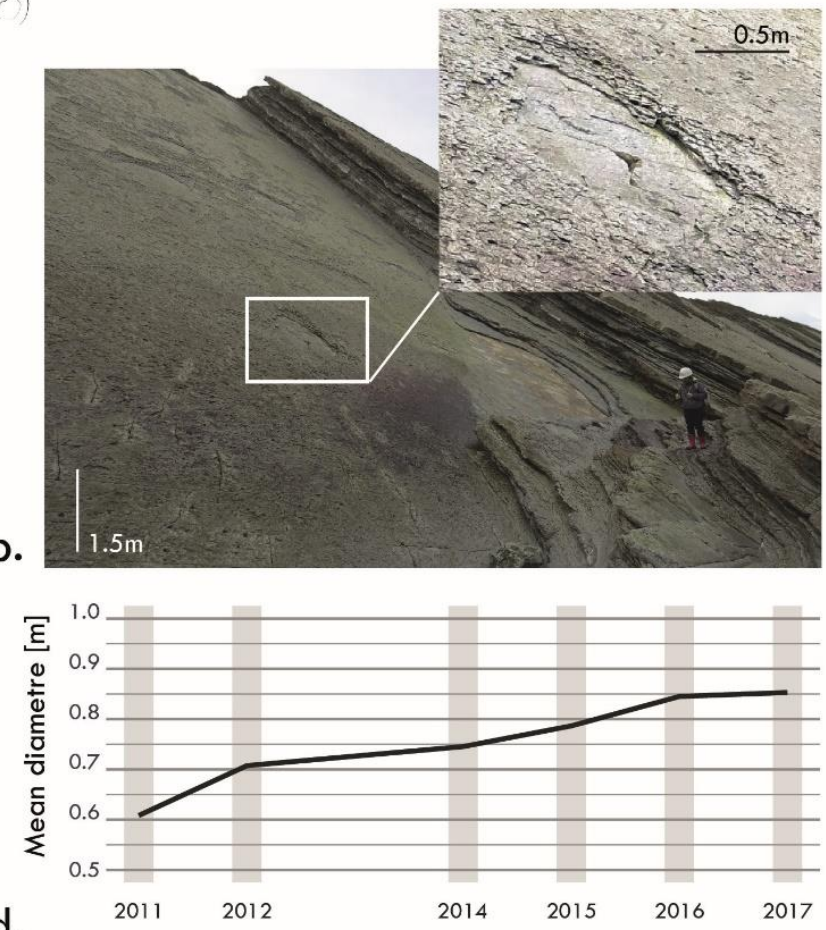

d.

Figure 14: Presentation of elliptical depression erosion phenomenon on a marly strata. A. Google earth view on 2016 where elliptical depressions are well visible; $b$. Photo from cliff foot and zoom on an elliptical depression; c. Evolution of number of elliptical depressions per year; $d$. evolution of average elliptical depression's radius.

The socket features left empty by the departed flakes have a conchoïdal morphology, analogous to the smooth curved ruptures observed in fractured glass. The rupture surface exhibits plumose structures, with micrometer-scale ribs and troughs, radiating outward from the center of each socket (Fossen, 2016). There is only ever one plume per socket focused at the center presumably coincident with the location of maximum stress, and reflects a surface morphology commonly described in geology. A fractographic interpretation of the outward radiating ribs indicates the rupture 
propagation direction (Fossen, 2016). Irrespective of what triggered the final rupture of individual platelets, the almost perfectly circular shape of elliptical depressions indicates that the detachment process is spatially uniform and occurs along the perimeter. Furthermore, their uniform vertical distribution across the cliff, rather than focused at marine dominated or aerial dominated elevation, is notable.

We note that the presence of elliptical depressions is limited to the $8 \mathrm{~cm}$ term $\mathrm{E}$ marls. Flaking stops at the roof of term $D$, though occasional scars etch the top of term $D$ at the intersection of joints (e.g. Figure 5). Term D scar frequency and dimensions are however much larger, with $10 \mathrm{~cm}$ edge lengths, rather than $3-5 \mathrm{~cm}$ edge lengths observed in term $\mathrm{E}$ beds (see Figure 5).

SfM monitoring shows that since this slab was first exposed in early 2011 , the number of elliptical depressions and their average surface area have progressively increased (Figure 14). The number of occurrences increased from 11 to 58 (Figure 14c), and the mean radii increased from $0.6 \mathrm{~m}$ to $0.85 \mathrm{~m}$ between 2011 and 2017 (Figure 14d). The total surface of the exposed marl bed is $1160 \mathrm{~m}^{2}$, and the surface area occupied by elliptical depressions increased tenfold in six years from $14 \mathrm{~m}^{2}$ to $144 \mathrm{~m}^{2}$. This rapid development indicates the prevalence, and potential significance of the process in the mass wasting of the surface. Elliptical depressions represent a total volume loss between 2011 to 2017 of $6.4 \mathrm{~m}^{3}$, amounting to $3.8 \%$ of our total cliff erosion estimate. Although this phenomenon only represents a part of the wider material flux, it is the only evidence of marl erosion at this site visible on the cliff face. The scarcity of elliptical-depression-bearing cliff sections compared to the abundant exposures of terms $C$ and $D$ fronting, suggests the cliff rapidly disaggregates by platelet detachment. 
In a similar fashion to that of concavity growth, the concentric expansion of elliptical depressions is remarkable. Unit blocks, or platelets, with volumes of cubic centimeters $\left(10^{-6}-10^{-5} \mathrm{~m}^{3}\right)$, rather than multiple cubic decimeters, detach along the free borders, exploiting existing fractures.

The polygonal, centimeter-scale $\left(10^{-2} \mathrm{~m}\right)$, planar shape of platelets are evocative of wetting and drying polygonal patterns (Goehring et al., 2010). An exploratory X-ray crystallography $(\mathrm{XRC})$ analysis run on platelets identified montmorillonite and kaolinite clay minerals, both of which are well known expansive clays. For wetting and drying as a key driver to be viable, however, dynamic water exchange must somehow be effective. Whether the actual calcitic structure stiffening the clays allows for water exchange remains to be proven. For now, we nevertheless speculate that term $\mathrm{E}$ beds exposed on the cliff face could well be affected by subaerial wetting and drying driven by the presence of swelling clays. Incremental platelet detachment leads to elliptical depression development over the entire cliff height through time. Elliptical depressions reset cliff face topography, eroding back to the strong underlying term $D$ limestone bed.

\section{Discussion}

\section{Method and general results}

The use of 3D data (SfM or LiDAR) has become common for monitoring cliff face evolution. The originality of our methodology for qualifying meaningful differences comes from the way the erosion signal was teased out of a series other obscuring signals. These are typical in this type of approach, and mirror the use of noise-based detection threshold in monitoring actively failing cliff faces (Dewez et al., 2013; Giuliano, 2015; Williams et al., 2018). A bias evident as long wavelength doming effect has been described in the literature and previously explained by inaccurate camera 
parameters inverted by SfM methods (Giuliano et al., 2013; James and Robson, 2014; Wackrow and Chandler, 2008). While our ground-based survey design explicitly included oblique shots to counter-act this defect, a residual error remained. More extensive control targets deployed within each campaign would have been beneficial, but where this is in retrospect not possible, we propose here a GIS-based technique for modelling and removing spatial biases. Further, we propose a replicable method to identify spurious differences in poorly reconstructed sections of 3D point clouds with a random forest classification algorithm common in data science research. This method was designed to be easy to use and adaptable to other features difficult to reconstruct in 3D due to narrow baseline stereoscopic conditions.

We monitored the erosion of Socoa cliffs as they represent a specific case of a cliff carved in a highly stratified monocline with a steep average dip at $45^{\circ}$. Socoa Cliff erosion rate ranges between $3.4 \mathrm{~mm} / \mathrm{yr}(2011$ - 2017 period) and $10.8 \mathrm{~mm} / \mathrm{yr}$ (1954 2008 period). These rates are in agreement with retreat rate data reported by Prémaillon et al., (2018) who anticipate centimeter-scale erosion rates for hard rocks cliffs based on a meta-analysis of global cliff monitoring studies (classified with the Hoek and Brown (1997) rock mass strength criterion). On a broader level, this suggests that the Socoa cliffs erode like hard rock cliffs. Turbidite term C and D, being medium strong to strong rocks (Hoek and Brown, 1997), set the overall pace of erosion. The presence of term $E$ beds in the sedimentary pile, despite being weak to very weak, and hence weakening the overall rock mass, are not sufficient to shift cliff erosion into the domain of soft rock cliffs.

These results are also consistent with other monitoring data from flysch coasts. For example, median rates of erosion of $17 \mathrm{~mm} / \mathrm{yr}$ in New Zealand (de Lange and Moon, 2005; Gulayev and Buckeridge, 2004) and in Portugal (Neves and Pereira, 1999) have 
been observed. Moreover, we provide new data to update the figure of $100 \mathrm{~mm} / \mathrm{yr}$ tentatively proposed by Aubié et al., (2009) for the 1954 - 2008 period. This illustrates how new techniques can be used to re-evaluate old or archived data.

\section{Fracture pattern characteristics}

The SfM study showed a clear spatio-temporal erosion pattern across the cliff. Erosion was focused around concavities, where many bed edges preferentially experience erosion. Erosion is commonly focused upon a structural defect, such as fracturedefined weaknesses, and has been shown to expand radially from this point. This is observed at centimeter-scale $\left(10^{-2} \mathrm{~m}\right)$ up to meter scale $\left(10^{0} \mathrm{~m}\right)$. This spatial pattern is strongly controlled by fracture geometry and character. These are: (i) infinite fractures, affecting the whole cliff rock mass; and (ii) finite fractures limited to one mechanical layer in thickness, such as joints, and spanning length of centimeters to several tens of meters. Infinite discontinuities are of two types at this site: stratification and faults. Stratification is parallel to the coast and dips at $40-45^{\circ}$ sets the cliff profile. The stratification surface frequency is centimeter- $\left(10^{-2} \mathrm{~m}\right)$ to decimeter-scale $\left(10^{-1} \mathrm{~m}\right)$. The stratification surface daylights laterally where beds encounter tectonic fractures, as well as at the top of the cliff, where stratification surfaces outcrop. If destabilized, slab collapse is limited in depth and only affects a few decimeters thickness of turbiditic beds. This provides a limit for assessing hazard associated with cliff top retreat. Stratification is also observed to guide erosion towards the cliff top. An impending collapse risk exists where wide concavities undermine the stratification surface beneath. The at risk cliff section is seaward of the boundary where the stratification surface outcrops. Using this, it is now possible to identify at risk locations along the coastal path and D912 road to identify possible occurrences of such a compromising cliff and structural configuration. 
Faults in the monitored cliff section are of two types: normal faults with occasional lateral slip, and reverse faults. Normal faults have a strike orthogonal $\left( \pm 15^{\circ}\right)$ to the stratification of the cliff rock mass. Faults commonly host concavities and expose stratigraphic surfaces along the flanks of these features. Fault dip is also distinct to $\left(>25^{\circ}\right)$ the bedding dip. The fault dip may influence the concavity vertical extent, although further investigation is required to demonstrate this. Reverse faults fracture bedding at much shallower angles ( $\pm 30^{\circ}$ to bedding strike, $5^{\circ}$ to bedding dip). We observe that reverse faults do not host well-developed concavities. This difference of morphological behavior is probably attributed to the fracture angle with respect to assailing forces, rather than to the tectonic style of faulting itself.

For finite fracturing, we see that joints bound jagged bed edges (Figure 4). This jagged morphology reflects the surfaces delimiting individual blocks that were quarried out of the cliff. Each bed has a joint spacing specific to its rock strength and thickness. Regionally $\left(10^{3}-10^{4} \mathrm{~m}\right)$, the $\mathrm{J} 1$ family parallels the $\mathrm{N} 070^{\circ} \mathrm{E}$ trend of the landward anticline (Mulder et al., 2009). At bed level, joint family J1 traces (Figure 4 and Figure 5) crudely parallel to the bedding strike with meter-scale $\left(10^{0} \mathrm{~m}\right)$ persistence. In decimeter-thick, medium-strong to strong beds, the $\mathrm{J} 1$ joint spacing is multi-decimeterscale $\left(10^{-1} \mathrm{~m}\right)$ across the bedding strike. This joint orientation and spacing delimits blocks with strike-parallel elongation. Joint family J2 (Figure 4 and Figure 5) is orthogonal to J1. J2 joints link J1 joints and terminate on them. J2 joints have decimeter-scale $\left(10^{-1} \mathrm{~m}\right)$ persistence for medium-strong to strong decimeter-thick beds. Orientation of the $\mathrm{J} 2$ planes is crudely parallel to bedding dip-direction, with spacing of a few decimeters $\left(10^{-1} \mathrm{~m}\right)$. Together, J1, J2 and stratification fracture sets delimit blocks as flat and broad pieces, the dimensions of which are controlled by the thickness (i.e. spacing of stratification) of the beds (e.g. Faÿ-Gomord et al., 2018). This 
combination of finite and infinite fractures defines the shape and size properties of rock exposed to erosion and plucking. To set an example, term $\mathrm{D}$ blocks can reach dimensions of $20 \mathrm{~cm}$ thickness, $80 \mathrm{~cm}$ length, and $60 \mathrm{~cm}$ in width. This volume of rock represents an approximate weight of $240 \mathrm{~kg}$ (with density of $2.5 \mathrm{~g} / \mathrm{cm}^{3}$ ). Notably, this mass of block is of a comparable magnitude to the threshold block mass deemed too heavy to pluck, as discussed by Scott and Wohl (2019) and Whipple et al. (2000).

Rock strength, approached through the Hoek and Brown (1997) rock mass strength classification, distinguishes two layer types: weak and strong. This strength difference is well-expressed in the morphology of the cliff. Weak beds clearly erode faster than strong beds. On the cliff face, where unconstrained, unit blocks described as platelets detach and collapse continually from weak term $E$ beds. Along cave flanks, we observe that weak beds are also deeply recessed alongstrike (e.g. Figure 4). The small-scale fracture pattern and polygonal shape at centimeter-scale $\left(10^{-2} \mathrm{~m}\right)$, and millimeter-scale $\left(10^{-3} \mathrm{~m}\right)$ block thickness, as well as the weak matrix strength itself, strongly control this morphology. We associate this form of erosion to the loosening process involved in bedrock river plucking (e.g. Scott and Wohl, 2019; Whipple et al., 2000) and rocky

shore platform erosion (e.g. Naylor et al., 2012). Such large depressions behind frontal beds exposes them to assailing forces both from the front (landward-heading) and from the back (seaward-going), where wave action clearly has a directional effect (Figure 1d).

Mechanically, free-standing beds along concavity flanks resemble beams or veils where different forces apply. The obliquity of bedding makes the pattern of forces more complex than if it were just a horizontal cantilever situation (e.g. Young and Ashford, 2008). Vertically, gravity pulls the slab down with greater effect the further the bed 
protrudes from the supporting bed underneath. The longer the beam, the larger the tension imposed. However, individual joint defined blocks are held in place by friction within the rock mass along fractures where the rock is broken, and where the weight of the rock contacts upslope-facing joints. With fracture sets oblique to gravity, bedding strike-parallel orientation of $\mathrm{J} 1$ joint set inhibit rockfall. The $\mathrm{J} 2$ joint set, on the contrary, as more vertical, offers less resistance. Specific investigation of fracture surfaces, and a full kinematic analysis of the rock mass, is needed to document how these orientations modulate coastal erosion rates (e.g. Kimber et al., 1998).

The flanks of concavities are more deeply recessed at elevations that become inundated by the tide. This means that strong beds overarching lateral concavities remain draped over the cliff face, exposing both their surface, and eroded lower basal surface. Incident waves exert landward pressure, but cliff-reflected waves also have the possibility to exert pressure seaward from under the slab, particularly with specific wave shape that leads to high energy impacts (e.g. Thompson et al., 2019). With these two horizontal force vectors, joint set $\mathrm{J} 1$ resists erosion with its landward dipping surface. J2 being more vertical offers less resistance to horizontal forces. Further work is required to document the ease with which blocks can escape their socket.

The lateral growth of concavities into medium-strong to strong beds develops an elliptical erosion pattern. The lateral recession rate of edges is faster than concurrent vertical erosion, as already identified on shore platforms (Buchanan et al., 2020; Dornbusch and Robinson, 2011; Regard et al., 2013). This pattern results from a combination of factors: (i) the obliquity of beds, which are dipping exactly half-way between vertical and horizontal, making the rock mass weight rest stably on the cliff foot and with a repose angle lower than friction the angle; (ii) the obliquity of faults with respect to sedimentary strata and to maximum wave forces; and (iii) the obliquity of 
joints inherited from regional tectonics and orogenic history of the Pyrenees mountain range.

Our study focused on two specific expressions of erosion to explore the specific role of fractures: elliptical depressions and concavities. In both cases, as soon as an instability is initiated, it propagates along both types of infinite discontinuity identified. Concavities mainly develop along faults and propagate deep inside the cliff rock mass. However, a small number are observed not to be rooted in a fault, but when this occurs meter-deep strata-bound joints can be observed on the side of the concavity and may explain the penetration of the erosion at these locations. This is the case of concavity \#2, where a fracture probably initiated the destabilization, which then progressed radially with a lateral preference following the stratigraphy. The depth of rock lost here is defined by the thickness of the mechanical beds (beds hosting strata-bound fractures). The same phenomenon occurs at the elliptical depressions, albeit it a smaller scale. Once initiated at a weak point, erosion develops radially through fracturing until it reaches a layer that does not have the same fracture pattern, which stops the propagation. Here, erosion could be called "fracture limited".

\section{Modelling cliff evolution}

We summarize our observations of cliff erosion by proposing a conceptual model for the evolution of the Socoa Cliff, illustrated in Figure 15:

- Nucleation: initial destabilization of the cliff foot, likely exploiting fractures which enable block plucking.

- Growth: plucking progresses around the concavity by block detachment, expanding the concavity sideways and upward directed by stratigraphic surfaces. Between strong limestone strata, marl beds erode quickly, 
undercutting the overlying limestone block and offering more surface to assailing forces. This stage is illustrated by concavity \#5 (Figure 13). Growth of the cliff concavity eventually breaches the cliff top and causes retreat. If the fracture stops, so does plucking.

- Crisis: Occurrence of a large slab-scale sliding failure. This final stage affects the top of the cliff. It is the event that will be captured in calculations of cliff-top retreat rate as an indicator of cliff erosion (e.g. Figure 15). Notably, this is the final stage was initiated much earlier, through the sequence described above.

\section{Nucleation}

Initiation of unstability

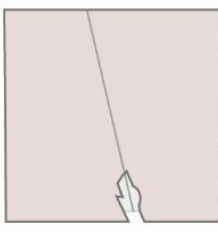

Time

\section{Growth}

Lateral developpement of cavity around initial nucleus by block detachement at edges
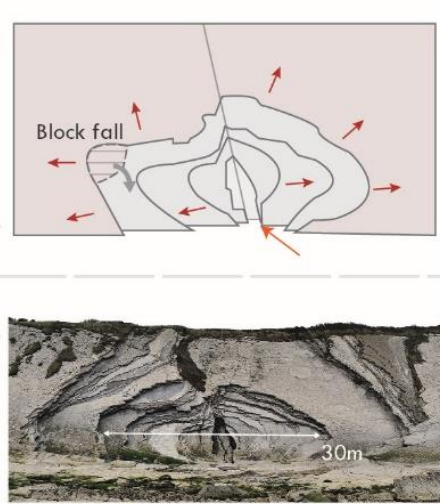

Concavity erosion reaches cliff top
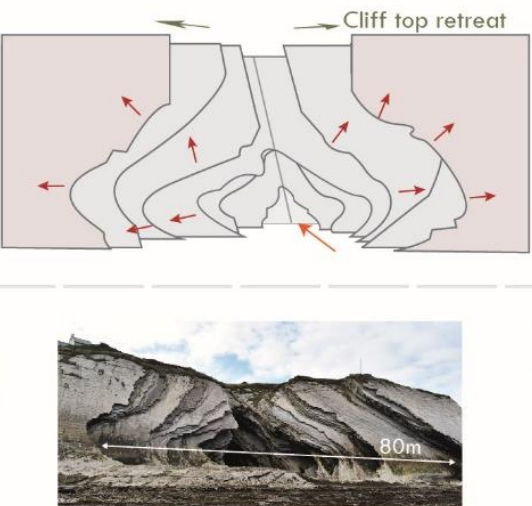

\section{Crisis}

A big rare rockfall event occurs.

Cliff top retreat dramatically. Lateral erosion keep going.

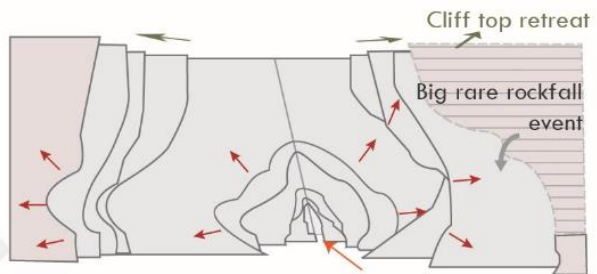

$2011,18^{\text {th }}$ february

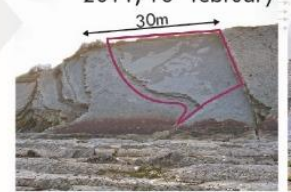

$2011,4^{\text {th }}$ april

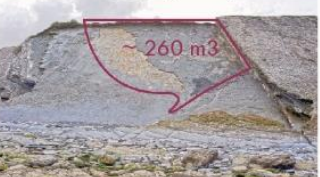

Figure 15: Socoa cliff evolution conceptual model.

The upward and lateral migration and spatial clustering of erosion and rockfall was also observed by Rosser et al., (2013), in a complex sub-horizontally interbedded sedimentary cliff. Rosser et al., (2013) highlighted that, after a first destabilisation triggered by marine action near cliff base, upward failure propagation is modulated by lithological strength and rock mass architecture. We do observe the same process here: concavities are initiated by marine erosion processes around a weakness (fracture), and then failure propagates radially. The spatial distribution of erosion is 
responsible for the current cliff shape, including both concavities, elliptical depressions and large structural surfaces that together constitute the cliff face.

We observed spatial variations of retreat rate, with hotspots of erosion localized at and immediately around concavities. Meanwhile, we also observed that the cliff line in mapview and at cliff-scale $\left(10^{2}-10^{4} \mathrm{~m}\right)$ is somewhat linear. This linear form indicates that the long-term average erosion rate must be constant over the entire stretch of coast. During the monitoring period, the area in between the concavities has experienced an effective erosion deficit. In other words, to use an optics analogy, concavities behave as erosion "source points" from which erosion waves radiate. It may therefore be anticipated that short-term concavity erosion rates approximate better the long-term cliff recession rate.

This model proposes a moderate and episodic mode of cliff top retreat. Erosion occurs more continuously at the cliff foot, as confirmed by eroded volume vs height histograms in Figure 11 and the elliptic shape of receding bed edges. At equilibrium, smoothing out the effect of transient erosion waves, however, the cliff top decadal erosion must equate that of cliff base erosion. If the entire cliff retreated at a rate equivalent to basal erosion rate $(\sim 7.5 \mathrm{~mm} / \mathrm{yr})$ the total eroded volume during the monitoring period would amount to $560 \mathrm{~m}^{3}$ (or $100 \mathrm{~m}^{3} / \mathrm{yr}$, equivalent to an eroded mass of $250 \mathrm{t} / \mathrm{yr}$ ). This expected value, compared to the observed $170 \mathrm{~m}^{3}$, indicates a deficit of $390 \mathrm{~m}^{3}$ over this period. Crisis events like the 2011 large collapse $\left(270 \mathrm{~m}^{3}\right)$ must sporadically compensate for this deficit. It is tempting to evaluate the time between the process of nucleation proposed here, and the period needed for erosion to reach the cliff top. We estimate here that this is of the order of 60 years, for concavity \#5, which is the most rapidly eroding feature. A second estimate of this period corresponds to the time necessary to erode an entire slab sequence, comprising several $C$ to $E$ terms ( 0.5 to 1 
$\mathrm{m}$ thick), considering a basal mean erosion rate of $7.5 \mathrm{~mm} / \mathrm{yr}$. The necessary time span is between 65 and $130 \mathrm{yrs}$.

This study also addresses the larger debate about the coastal cliff-notching phenomenon advocated by, amongst others Sunamura (1994). Indeed, notches are observed in some rocks and their influence has been modelled (Thébaudeau et al., 2013). However, notches, as a cavity with meter-high semi-cylindrical cross-profile and horizontal continuous for tens- to hundreds-of-meter-long $\left(10^{1}-10^{2} \mathrm{~m}\right)$ morphology, occupying cliff foot within tidal reach are not present on every coast (e.g. Pirazzoli, 1986; Furlani et al., 2011; Pirazzoli and Evelpidou, 2013). The result of some models also suggests that erosion may not be so closely dependent on notch formation and progression (Rosser et al., 2013). Along the study area, we do not observe a clear notch of that sort, either, but we do observe nevertheless a high basal erosion. Erosion is laterally discontinuous, with an intensity set by crosscutting fault frequency. So, we can suggest that the rock mass fracture pattern holds some control on the morphological expression of or indeed presence of a notch. It could be possible that the fracture pattern, via enabling plucking, inhibits the development of laterally continuous notches. Concavities could be the morphological expression of notches in a context with a highly fractured rock mass, as here.

\section{Suggestions for models and research needs}

In order to predict the hazard associated with cliff recession and the erosion of rocky shorelines during glacial and interglacial cycles, it is necessary to model the overall dynamics of cliff recession. On decadal time scales, probabilistic models are based on chronicles of the last few years or few decades in the best documented cases (e.g. Dussauge-Peisser et al., 2002 for mountainous environments). However, our data show that the hazard of cliff collapse and retreat varies over time, depending on where 
a cliff section sits on a longer cycle of erosion. For cliffs made up of steeply dipping layers such as here, our data suggest that in order to determine recession hazard, characterising the current state (phase 1, 2 or 3 in our model) would be highly beneficial.

Numerical models of cliff recession over tens of thousands of years are based on a simpler relationship between a mean foreshore platform erosion and the mean force exerted or energy dissipated by breaking waves at the cliff base (e.g. Anderson et al., 1999; Trenhaile, 2002). These models are forced at any given elevation by known isostatic variations. Some models include different classes of wave heights to calculate average erosion but do not consider wave variability over time (e.g. Trenhaile, 2002). In addition, these models generally operate along 2D profiles perpendicular to the coast. Although our study corresponds to a particular lithological case, our data suggest several avenues to improve these landscape evolution models. For example, a numerical model describing the millennial evolution of the Socoa cliffs should include a fracture density that controls the number of erosion nucleation points, a concavity growth rate that controls the characteristic time between two crises, and a threshold of concavity size and distance between concavities to produce wider scale collapse. It is likely that the growth rate of concavities depends on the impact of waves, but this relationship remains to be determined and constitutes a clear research need. This relationship is fundamental for more accurate prediction of long-term coastal recession. A suitable model could be $2 \mathrm{D}$ or $3 \mathrm{D}$, as it would take into account the longitudinal evolution of the cliff, with key features identified here as varying fracture density and inter-concavity distance, which are not commonly represented in existing models. Such a model could therefore also be used to study the evolution of coastal sinuosity that could emerge from longitudinal variations in the state of the cliff 
(nucleation, growth or crisis) that might be fundamentally related to rock mass structure. Finally, the nucleation, growth and crisis sequence builds on and has relevance to conceptual models of interface evolution proposed in other disciplines. Percolation theory (Stark, 1994), for example, includes these three phases and has been used to understand many physical phenomena such as phase transitions. The crest line recession of a plateau has also been studied by comparing the competition between different clustering phenomena such as invasion-percolation (possible analogue of nucleation phase 1), Eden growth (possible analogue of phase growth 2) and diffusion-limited aggregation (possible analogue of phase crisis 3) (Stark, 1994). New numerical models of coastal evolution could benefit from further engagement in this theoretical corpus.

\section{Conclusion}

The $\sim 30 \mathrm{~m}$ high Socoa Cliffs are formed in monoclinal flysch strata of sequences of turbiditic beds made of medium strong to strong (limestone beds) and weak to very weak (marl beds). The cliffs are retreating at an average rate of 3 to $11 \mathrm{~mm} / \mathrm{yr}$. This corresponds to an eroded volume of $\sim 0.09-0.33 \mathrm{~m} 3 / \mathrm{m} / \mathrm{yr}(220-830 \mathrm{~kg} / \mathrm{m} / \mathrm{yr})$, but we highlight that this average value hides considerable variations in erosion in both space and time. Such rates are coherent with strong rock mass cliffs reported in the literature.

Spacially, the erosion appears to be enhanced where structurally directed by the fracture pattern of the rock mass. Bed edges are exposed along concavity flanks, where faults or deep-reaching strata-bound joints penetrate the rock mass for several meters. Most of the rock falls can be considered as occurring in two categories: some affect a single but entire flysch limestone bed, the others are small and affect the surface of the marl layers only. The falling rock slices are thus limited in depth to $\sim 0.5$ 
- $1 \mathrm{~m}$, the typical flysch strata thickness at this site. On the contrary, falls of rock slices can be extensive along and up the cliff, failing in a single event up to a couple of hundred square meters. Our preferred scenario based upon our observations is that erosion nucleates near to the cliff base, preferentially at the location of discontinuities such as faults. Then erosion propagates in both depth and preferentially laterally expanding concavities.

Finally, the cliff face between concavities may collapse, potentially during discrete large scale collapse or crisis events. Over time, erosion is a relatively continuous process at the cliff base within concavities, while change at the cliff top is rarer, occurring here typically once every 60 to $130 \mathrm{yrs}$.

On rock coasts, plucking processes have become increasingly recognized and quantified on shore platforms (e.g. Cullen and Bourke, 2018). By contrast, they have been more overlooked on cliffs. In this study, plucking is clearly shown to drive cliff erosion. Fractures, in the form of stratification surfaces and faults are infinite at cliff scale and direct erosion. Joint frequency delimits individual blocks, while bedding frequency controls their thickness. The relative orientation of these fractures with respect to gravity and wave attack modulates erosion. In horizontally stratified sedimentary rocks, cliff recession is likely to be controlled by faults, stratification and joints in a similar manner, but more complex erosion morphologies may hamper the identification of plucking as a morphogenetic process. Now is a good time to catch up with other fields of geomorphology and start documenting how both processes mediate rock control to drive rock coast erosion. 


\section{References}

Anderson, R.S., Densmore, A.L., Ellis, M.A., 1999. The generation and degradation of marine terraces. Basin Research 11, 7-19.

Aubié, S., Mallet, C., Favennec, J., 2011. Caractérisation de l'aléa érosion (2020-2040) de la Côte Aquitaine dans le cadre de l'étude stratégique de gestion du trait de côte Observatoire de la Côte Aquitaine (No. BRGM/RP-59095-FR). BRGM.

Aubié, S., Mathon, C., Genna, A., 2009. Exposition de la route de la Corniche aux phénomènes naturels (commune d'Urrugne, 64) - Observatoire de la Côte Aquitaine (No. BRGM/RP-57301-FR). BRGM.

Barlow, J., Lim, M., Rosser, N., Petley, D., Brain, M., Norman, E., Geer, M., 2012. Modeling cliff erosion using negative power law scaling of rockfalls. Geomorphology 139-140, 416-424. https://doi.org/10.1016/j.geomorph.2011.11.006

Benjamin, J., Rosser, N.J., Brain, M.J., 2020. Emergent characteristics of rockfall inventories captured at a regional scale. Earth Surf. Process. Landforms esp.4929. https://doi.org/10.1002/esp.4929

Benumof, B.T., Storlazzi, C.D., Seymour, R.J., Griggs, G.B., 2000. The relationship between incident wave energy and seacliff erosion rates: San Diego County, California. Journal of Coastal Research 1162-1178.

Bezerra, M.M., Moura, D., Ferreira, Ó., Taborda, R., 2011. Influence of Wave Action and Lithology on Sea Cliff Mass Movements in Central Algarve Coast, Portugal. Journal of Coastal Research 275, 162-171. https://doi.org/10.2112/JCOASTRES-D-11-00004.1

Breiman, L., 2001. Random Forests. Machine Learning 45, 5-32. https://doi.org/10.1023/A:1010933404324

Brunetti, M.T., Guzzetti, F., Rossi, M., 2009. Probability distributions of landslide volumes. Nonlinear Processes in Geophysics 16, 179-188.

Buchanan, D.H., Naylor, L.A., Hurst, M.D., Stephenson, W.J., 2020. Erosion of rocky shore platforms by block detachment from layered stratigraphy. Earth Surface Processes and Landforms 45, 1028-1037. https://doi.org/10.1002/esp.4797

Caplain, B., 2011. Etude expérimentale de l'érosion d'un massif de sable cohésif par une houle monochromatique. Université de Toulouse.

Caplain, B., Astruc, D., Regard, V., Moulin, F.Y., 2011. Cliff retreat and sea bed morphology under monochromatic wave forcing: Experimental study. Comptes Rendus Geoscience 343, 471-477. https://doi.org/10.1016/j.crte.2011.06.003

Costa, S., Maquaire, O., Letortu, P., Thirard, G., Compain, V., Roulland, T., Medjkane, M., Davidson, R., Graff, K., Lissak, C., Delacourt, C., Duguet, T., Fauchard, C., Antoine, R., 2019. Sedimentary Coastal Cliffs of Normandy: Modalities and Quantification of Retreat. coas 88, 46-60. https://doi.org/10.2112/SI88-005.1

Cruslock, E.M., Naylor, L.A., Foote, Y.L., Swantesson, J.O.H., 2010. Geomorphologic equifinality: A comparison between shore platforms in Hoga Kusten and Faro, Sweden and the Vale of Glamorgan, South Wales, UK. Geomorphology 114, 78-88. https://doi.org/10.1016/j.geomorph.2009.02.019

Cullen, N.D., Bourke, M.C., 2018. Clast abrasion of a rock shore platform on the Atlantic coast of Ireland: Clast abrasion of a rock shore platform. Earth Surface Processes and Landforms 43, 2627-2641. https://doi.org/10.1002/esp.4421 
Daigneault, M., 2001. Processus d'altération / érosion à l'interface océan / continent / atmosphère : aspects quantitatifs et semi-quantitatifs : exemple des falaises de l'Est du Canada (Gaspésie) (PhD Thesis).

de Lange, W.P., Moon, V.G., 2005. Estimating long-term cliff recession rates from shore platform widths. Engineering Geology 80, 292-301. https://doi.org/10.1016/j.enggeo.2005.06.004

de Vilder, S.J., Rosser, N.J., Brain, M.J., 2017. Forensic analysis of rockfall scars. Geomorphology 295, https://doi.org/10.1016/j.geomorph.2017.07.005

Dewez, T., Rohmer, J., Closset, L., 2007. Laser survey and mechanical modeling of chalky sea cliff collapse in Normandy, France, in: Proceedings of the International Conference on Landslides and Climate Change, Ventnor, England. pp. 281-288.

Dewez, T.J.B., Leroux, J., Morelli, S., 2016. Cliff collapse hazard from repeated multicopter UAV acquisitions: return on experience. ISPRS - International Archives of the Photogrammetry, Remote Sensing and Spatial Information Sciences XLI-B5, 805-811. https://doi.org/10.5194/isprsarchives-XLI-B5-8052016

Dewez, T.J.B., Rohmer, J., Regard, V., Cnudde, C., 2013. Probabilistic coastal cliff collapse hazard from repeated terrestrial laser surveys: case study from Mesnil Val (Normandy, northern France). Journal of Coastal Research 65, 702-707.

Dornbusch, U., Robinson, D.A., 2011. Block removal and step backwearing as erosion processes on rock shore platforms: a preliminary case study of the chalk shore platforms of south-east England. Earth Surf. Process. Landforms 36, 661-671. https://doi.org/10.1002/esp.2086

Dornbusch, U., Robinson, D.A., Moses, C.A., Williams, R.B.G., 2008. Temporal and spatial variations of chalk cliff retreat in East Sussex, 1873 to 2001. Marine Geology 249, 271-282. https://doi.org/10.1016/j.margeo.2007.12.005

Dussauge-Peisser, C., Helmstetter, A., Grasso, J.-R., Hantz, D., Desvarreux, P., Jeannin, M., Giraud, A., 2002. Probabilistic approach to rock fall hazard assessment: potential of historical data analysis. Natural Hazards and Earth System Science 2, 15-26.

Earlie, C.S., 2015. Field observations of wave induced coastal cliff erosion, cornwall, UK. Plymouth University.

Earlie, C.S., Masselink, G., Russell, P.E., Shail, R.K., 2015. Application of airborne LiDAR to investigate rates of recession in rocky coast environments. Journal of Coastal Conservation 19, 831-845. https://doi.org/10.1007/s11852-014-0340-1

Faÿ-Gomord, O., Verbiest, M., Lasseur, E., Caline, B., Allanic, C., Descamps, F., Vandycke, S., Swennen, R., 2018. Geological and mechanical study of argillaceous North Sea chalk: Implications for the characterisation of fractured reservoirs. Marine and Petroleum Geology 92, 962-978. https://doi.org/10.1016/j.marpetgeo.2018.03.037

Fossen, H., 2016. Structural geology. Cambridge University Press.

Furlani, S., Cucchi, F., Biolchi, S., Odorico, R., 2011. Notches in the Northern Adriatic Sea: Genesis and development. Quaternary International, Tectonic Contribution to Relative Sea Level Change 232, 158-168. https://doi.org/10.1016/j.quaint.2010.06.010

Genter, A., Duperret, A., Martinez, A., Mortimore, R.N., Vila, J.-L., 2004. Multiscale fracture analysis along the French chalk coastline for investigating erosion by cliff collapse. https://doi.org/10.1144/GSL.ENG.2004.020.01.04 
Girardeau-Montaut, D., 2011. Cloudcompare-open source project. OpenSource Project.

Giuliano, J., 2015. Erosion des falaises de la région Provence-Alpes-Côte d'Azur: évolution et origine de la morphologie côtière en Méditerranée. Université Nice - Sophia Antipolis.

Giuliano, J., Godard, V., Lebourg, T., Dewez, T.J.B., Tric, E., Marçot, N., 2013. Large scale structural control on regional coastline orientations: example from Southeastern France. Journal of Coastal Research 165, 1687-1691. https://doi.org/10.2112/SI65-285.1

Goehring, L., Conroy, R., Akhter, A., Clegg, W.J., Routh, A.F., 2010. Evolution of mudcrack patterns during repeated drying cycles. Soft Matter 6, 3562. https://doi.org/10.1039/b922206e

Gulayev, S.A., Buckeridge, J.., 2004. Terrestrial methods for monitoring cliff erosion in a urban environment. Journal of Coastal Research 20, 871-878.

Hantz, D., Colas, B., Dewez, T., Lévy, C., Rossetti, J.-P., Guerin, A., Jaboyedoff, M., 2020. Caractérisation quantitative des aléas rocheux de départ diffus. Rev. Fr. Geotech. 2. https://doi.org/10.1051/geotech/2020011

Himmelstoss, E.A., Henderson, R.E., Kratzmann, M.G., Farris, A.S., 2018. Digital Shoreline Analysis System (DSAS) version 5.0 user guide (USGS Numbered Series No. 2018-1179), Open-File Report. U.S. Geological Survey, Reston, VA.

Hoek, E., Brown, E.T., 1997. Practical estimates of Rock Mass Strength. International Journal of Rock Mechanics and Mining Sciences 34, 1165-1186.

James, M.R., Robson, S., 2014. Mitigating systematic error in topographic models derived from UAV and ground-based image networks. Earth Surface Processes and Landforms 39, 1413-1420. https://doi.org/10.1002/esp.3609

Kimber, O.G., Allison, R.J., Cox, N.J., 1998. Mechanisms of Failure and Slope Development in Rock Masses. Transactions of the Institute of British Geographers 23, 353-370. https://doi.org/10.1111/j.0020-2754.1998.00353.x

Lague, D., Brodu, N., Leroux, J., 2013. Accurate 3D comparison of complex topography with terrestrial laser scanner: Application to the Rangitikei canyon (N-Z). ISPRS Journal of Photogrammetry and Remote Sensing 82, 10-26. https://doi.org/10.1016/j.isprsjprs.2013.04.009

Letortu, P., 2013. Le recul des falaises crayeuses haut-normandes et les inondations par la mer en Manche centrale et orientale: de la quantification de l'aléa à la caractérisation des risques induits. Caen Basse Normandie.

Letortu, P., Costa, S., Bensaid, A., Cador, J.-M., Quénol, H., 2014. Vitesses et modalités de recul des falaises crayeuses de Haute-Normandie (France): méthodologie et variabilité du recul. Géomorphologie: relief, processus, environnement 20, 133-144. https://doi.org/10.4000/geomorphologie.10588

Letortu, P., Costa, S., Maquaire, O., Delacourt, C., Augereau, E., Davidson, R., Suanez, S., Nabucet, J., 2015. Retreat rates, modalities and agents responsible for erosion along the coastal chalk cliffs of Upper Normandy: The contribution of terrestrial laser scanning. Geomorphology 245, 3-14. https://doi.org/10.1016/j.geomorph.2015.05.007

Lim, M., Rosser, N.J., Allison, R.J., Petley, D.N., 2010. Erosional processes in the hard rock coastal cliffs at Staithes, North Yorkshire. Geomorphology 114, 12-21. https://doi.org/10.1016/j.geomorph.2009.02.011

$\begin{array}{llll}\text { Maillet, G., 2014. } & \text { SPLASHALIOT-01 } & \text { cruise,Haliotis } & \text { R/V. }\end{array}$ https://doi.org/10.17600/14011400 
Mortimore, R.N., 2012. Making sense of Chalk: a total-rock approach to its Engineering Geology. Quarterly Journal of Engineering Geology and Hydrogeology 45, 252334. https://doi.org/10.1144/1470-9236/11-052

Mortimore, R.N., Lawrence, J., Pope, D., Duperret, A., Genter, A., 2004. Coastal cliff geohazards in weak rock: the UK Chalk cliffs of Sussex, in: Mortimore, R.N., Duperret, A. (Eds.), Coastal Chalk Cliff Instability. Geological Society, London, Engineering Geology special Publication, pp. 3-31.

Moses, C., Robinson, D., 2011. Chalk coast dynamics: Implications for understanding rock coast evolution. Earth-Science Reviews 109, 63-73. https://doi.org/10.1016/j.earscirev.2011.08.003

Mulder, T., Razin, P., Faugeres, J.-C., 2009. Hummocky cross-stratification-like structures in deep-sea turbidites: Upper Cretaceous Basque basins (Western Pyrenees, $\quad$ France). Sedimentology 56, 997-1015. https://doi.org/10.1111/j.1365-3091.2008.01014.x

Naylor, L.A., Coombes, M.A., Viles, H.A., 2012. Reconceptualising the role of organisms in the erosion of rock coasts: A new model. Geomorphology, Special Issue Zoogeomorphology and Ecosystem Engineering Proceedings of the 42nd Binghamton Symposium in Geomorphology, held 21-23 October 2011 157-158, 17-30. https://doi.org/10.1016/j.geomorph.2011.07.015

Naylor, L.A., Stephenson, W.J., 2010. On the role of discontinuities in mediating shore platform erosion. Geomorphology 114, 89.

Neves, M., Pereira, A.R., 1999. The interaction between marine and subaerial processes in the evolution of rocky coasts: The example of Castelejo (southwest Portugal). BOLETIN-INSTITUTO ESPANOL DE OCEANOGRAFIA 15, $251-$ 258.

Peel, M.C., Finlayson, B.L., Mcmahon, T.A., 2007. Updated world map of the KöppenGeiger climate classification. Hydrology and Earth System Sciences Discussions 4, 439-473.

Pirazzoli, P., 1986. Marine notches, in: Sea-Level Research. Springer, pp. 361-400.

Pirazzoli, P.A., Evelpidou, N., 2013. Tidal notches: A sea-level indicator of uncertain archival trustworthiness. Palaeogeography, Palaeoclimatology, Palaeoecology 369, 377-384. https://doi.org/10.1016/j.palaeo.2012.11.004

Prémaillon, M., Regard, V., Dewez, T.J.B., Auda, Y., 2018. GlobR2C2 (Global Recession Rates of Coastal Cliffs): a global relational database to investigate coastal rocky cliff erosion rate variations. Earth Surface Dynamics 6, 651-668. https://doi.org/10.5194/esurf-6-651-2018

Rault, C., Dewez, T.J.B., Aunay, B., 2020. STRUCTURE-FROM-MOTION PROCESSING OF AERIAL ARCHIVE PHOTOGRAPHS: SENSITIVITY ANALYSES PAVE THE WAY FOR QUANTIFYING GEOMORPHOLOGICAL CHANGES SINCE 1978 IN LA RÉUNION ISLAND, in: ISPRS Annals of Photogrammetry, Remote Sensing and Spatial Information Sciences. Presented at the XXIV ISPRS Congress, Commission II (Volume V-2-2020) 2020 edition, Copernicus $\mathrm{GmbH}$, pp. 773-780. https://doi.org/10.5194/isprsannals-V-2-2020-773-2020

Razin, P., 1989. Evolution techtono-sédimentaire alpine des Pyrénées Basques à l'ouest de la transformante de Pamplona (Province de Labourd). Université Bordeaux 2.

Regard, V., de Casamajor, M.-N., Maillet, G.M., Prémaillon, M., Caill-Milly, N., 2017. Quantification of a rock platform bioerosion by the sea urchin Paracentrotus 
lividus (Lamarck, 1816): the Basque Coast case (Bay of Biscay). Presented at the EGU Symposium, Vienna, Austria.

Regard, V., Dewez, T.J.B., Cnudde, C., Hourizadeh, N., 2013. Coastal chalk platform downwearing modulated by step backwearing and debris shielding: example from Normandy and Picardy (northern France). In: Conley, D.C., Masselink, G., Russell, P.E. and O'Hare, T.J. (eds.), Proceedings 12th International Coastal Symposium (Plymouth, England), Journal of Coastal Research Special Issue No. 65, 1692-1697.

Riquelme, A., Del Soldato, M., Tomás, R., Cano, M., Jordá Bordehore, L., Moretti, S., 2019. Digital landform reconstruction using old and recent open access digital aerial photos. Geomorphology 329, 206-223. https://doi.org/10.1016/j.geomorph.2019.01.003

Rohmer, J., Dewez, T.J.B., 2013. On the deviation of extreme sea-cliff instabilities from the power-law frequency-volume distribution: practical implications for coastal management In: Conley, D.C., Masselink, G., Russell, P.E. and O'Hare, T.J. (eds.), Proceedings 12th International Coastal Symposium (Plymouth, England), Journal of Coastal Research, 1698-1703.

Rosser, N., Lim, M., Petley, D., Dunning, S., Allison, R., 2007. Patterns of precursory rockfall prior to slope failure. Journal of Geophysical Research 112. https://doi.org/10.1029/2006JF000642

Rosser, N.J., Brain, M.J., Petley, D.N., Lim, M., Norman, E.C., 2013. Coastline retreat via progressive failure of rocky coastal cliffs. Geology 41, 939-942. https://doi.org/10.1130/G34371.1

Roulland, T., Maquaire, O., Costa, S., Compain, V., Davidson, R., Medjkane, M., 2019. Dynamique des falaises des Vaches Noires: analyse diachronique historique et récente à l'aide de documents multi-sources (Normandie, France). Géomorphologie: relief, processus, environnement 25, 37-55. https://doi.org/10.4000/geomorphologie.12989

Scott, D.N., Wohl, E.E., 2019. Bedrock fracture influences on geomorphic process and form across process domains and scales. Earth Surface Processes and Landforms 44, 27-45. https://doi.org/10.1002/esp.4473

Selby, M., 1980. A rock mass strength classification for geomorphic purposes: with tests from Antarctica and New Zealand. Zeit. fur Geomorph., NF 24, 31-51.

Selby, M.J., Hodder, A.P.W., 1993. Hillslope Materials and Processes, Oxford University Press. ed.

SHOM, 2016. Références Altimétriques Maritimes, 2016th ed. SHOM.

Stark, C.P., 1994. Cluster growth modeling of plateau erosion. J. Geophys. Res. 99, 13957-13969. https://doi.org/10.1029/94JB00610

Stark, C.P., Guzzetti, F., 2009. Landslide rupture and the probability distribution of mobilized debris volumes. Journal of Geophysical Research 114. https://doi.org/10.1029/2008JF001008

Stead, D., Wolter, A., 2015. A critical review of rock slope failure mechanisms: The importance of structural geology. Journal of Structural Geology 74, 1-23. https://doi.org/10.1016/j.jsg.2015.02.002

Stephenson, W.J., Kirk, R.M., 2000. Development of shore platforms on Kaikoura Peninsula, South Island, New Zealand II: The role of subaerial weathering 14.

Sunamura, T., 1994. Rock control in coastal geomorphic processes. International Journal of Rock Mechanics and Mining Sciences and Geomechanics Abstracts 32, 253-272. https://doi.org/10.1016/0148-9062(95)90024-Y

Sunamura, T., 1992a. Geomorphology of rocky coasts. J. Wiley. 
Sunamura, T., 1992b. Geomorphology of Rocky Coasts. John Wiley \& Sons, Chichester, UK.

Thébaudeau, B., Trenhaile, A.S., Edwards, R.J., 2013. Modelling the development of rocky shoreline profiles along the northern coast of Ireland. Geomorphology 203, 66-78. https://doi.org/10.1016/j.geomorph.2013.03.027

Thompson, C.F., Young, A.P., Dickson, M.E., 2019. Wave impacts on coastal cliffs: Do bigger waves drive greater ground motion? Earth Surface Processes and Landforms 44, 2849-2860. https://doi.org/10.1002/esp.4712

Trenhaile, A.., 2002. Modeling the development of marine terraces on tectonically mobile rock coasts. Marine Geology 185, 341-361. https://doi.org/10.1016/S0025-3227(02)00187-1

Trenhaile, A.S., 2015. Coastal notches: Their morphology, formation, and function. Earth-Science Reviews 150, 285-304. https://doi.org/10.1016/j.earscirev.2015.08.003

Trenhaile, A.S., 2000. Modeling the development of wave-cut shore platforms. Marine Geology 166, 163-178.

Vann Jones, E.C., Rosser, N.J., Brain, M.J., Petley, D.N., 2015. Quantifying the environmental controls on erosion of a hard rock cliff. Marine Geology 363, 230 242. https://doi.org/10.1016/j.margeo.2014.12.008

Wackrow, R., Chandler, J.H., 2008. A convergent image configuration for DEM extraction that minimises the systematic effects caused by an inaccurate lens model. The Photogrammetric Record 23, 6-18. https://doi.org/10.1111/j.14779730.2008.00467.x

Wenzel, K., Rothermel, M., Fritsch, D., Haala, N., 2013. Image acquisition and model selection for multi-view stereo. ISPRS - International Archives of the Photogrammetry, Remote Sensing and Spatial Information Sciences XL-5/W1, 251-258. https://doi.org/10.5194/isprsarchives-XL-5-W1-251-2013

Whipple, K.X., Hancock, G.S., Anderson, R.S., 2000. River incision into bedrock: Mechanics and relative efficacy of plucking, abrasion, and cavitation. GSA Bulletin 112, 490-503. https://doi.org/10.1130/00167606(2000)112<490:RIIBMA>2.0.CO;2

Williams, J.G., Rosser, N.J., Hardy, R.J., Brain, M.J., Afana, A.A., 2018. Optimising 4D surface change detection: an approach for capturing rockfall magnitudefrequency. Earth Surface Dynamics 6, 101-119. https://doi.org/10.5194/esurf6-101-2018

Wolters, G., Müller, G., 2008. Effect of Cliff Shape on Internal Stresses and Rock Slope Stability. Journal of Coastal Research 241, 43-50. https://doi.org/10.2112/050569.1

Young, A.P., Ashford, S.A., 2008. Instability investigation of cantilevered seacliffs. Earth Surface Processes and Landforms 33, 1661-1677. https://doi.org/10.1002/esp.1636

Young, A.P., Guza, R.T., Flick, R.E., O’Reilly, W.C., Gutierrez, R., 2009. Rain, waves, and short-term evolution of composite seacliffs in southern California. Marine Geology 267, 1-7. https://doi.org/10.1016/j.margeo.2009.08.008

Young, A.P., Guza, R.T., Matsumoto, H., Merrifield, M.A., O'Reilly, W.C., Swirad, Z.M., 2021. Three years of weekly observations of coastal cliff erosion by waves and rainfall. Geomorphology $375, \quad 107545$. https://doi.org/10.1016/j.geomorph.2020.107545 


\section{Acknowledgments}

BRGM and Midi-Pyrenees Region provided PhD funding for PM. This work benefited from additional support by SNO Dynalit and Université Paul Sabatier. INSU and OMP funded early photo campains. FEDER-project EZPONDA (PROJET EZPONDA - Études des paramètres mécaniques et chimiques à l'origine de l'altération des falaises rocheuses de la côte basque et des ouvrages de défense - impacts et vitesses d'érosion, financé par des fonds FEDER) funds LG's PhD, TD's time as well as new field acquisitions exploited in this manuscript. Larissa Naylor, one reviewer and the editor are acknowledged for their constructive comments.

TD wishes to express his gratitude to Prof Jim Chandler for his seminal and inspiring work bringing photogrammetry and geomorphology together. Thank you Jim for your kindness and influence you've had on my research life.

\section{Author Contributions}

Conceptualization: VR, TD and MP; Funding acquisition: VR and TD; Methodology: MP, TD, NR; Investigation and resources: MP, TD, VR, NR, LG; Supervision: TD and VR; Writing: all authors.

\section{Data Availability Statement}

The photo campaigns will soon be available through Dynalit website. Processed data is available on demand. 